\title{
The *hope-wh puzzle
}

\author{
Wataru Uegaki ${ }^{1}$ (i) $\cdot$ Yasutada Sudo ${ }^{2}$
}

Published online: 23 October 2019

(c) The Author(s) 2019

\begin{abstract}
Clause-embedding predicates come in three major varieties: (i) responsive predicates (e.g. know) are compatible with both declarative and interrogative complements; (ii) rogative predicates (e.g. wonder) are only compatible with interrogative complements; and (iii) anti-rogative predicates (e.g. hope) are only compatible with declarative complements. It has been suggested that these selectional properties are at least partly semantic in nature. In particular, it has been proposed that the anti-rogativity of negraising predicates like believe comes from the triviality in meaning that would arise with interrogative complements. This paper puts forward a similar semantic explanation for non-veridical preferential predicates such as hope, which are anti-rogative, unlike their veridical counterparts such as be happy, which are responsive.
\end{abstract}

Keywords Selectional restrictions - Attitude predicates - Clausal complementation · Question embedding · Preferential predicates

\section{Introduction}

Clause-embedding predicates can be classified into three types (Grimshaw 1979; Lahiri 2002; Theiler et al. 2019):

We would like to thank Sam Alxatib, Dominique Blok, Alexandre Cremers, Kajsa Djärv, Patrick D. Elliot, Donka Farkas, Jon Gajewski, Jane Grimshaw, Dan Lassiter, Louise McNally, Rick Nouwen, Floris Roelofsen, Maribel Romero, Jacopo Romoli, Bernhard Schwarz, Henriette de Swart, Aaron Steven White, as well as two anonymous reviewers for helpful comments and discussion. Earlier versions of this paper have been presented at the Selection Fest (Berlin 2017) and the Amsterdam Colloquium 2017. Finally, we gratefully acknowledge financial support from the Netherlands Organisation for Scientific Research (NWO; Grant Number: IG.18.023).

\footnotetext{
$\bowtie \quad$ Wataru Uegaki w.uegaki@ed.ac.uk

1 University of Edinburgh, Edinburgh, UK

2 University College London, London, UK
} 
- Responsive predicates, which can embed both declarative and interrogative complements, e.g. know.

- Rogative predicates, which can only embed interrogative complements, e.g. wonder.

- Anti-rogative predicates, which can only embed declarative complements, e.g. believe.

The main question we would like to tackle in this paper is how this variation should be accounted for. One possibility is to assume that each clause-embedding predicate comes with a lexical specification as to what kind of clause it syntactically selects for. This type of approach, however, is unsatisfactory on its own, given the stability and predictability of larger selectional patterns observed both intra- and cross-linguistically: predicates that have similar meanings generally exhibit the same selectional properties. For instance, we would like to explain why we do not find a version of know that is rogative or a version of wonder that is responsive. Considerations like this are taken as evidence that the core selectional properties are due to the lexical semantics of the predicates, although idiosyncratic syntactic properties are not necessarily excluded (Grimshaw 1979; Pesetsky 1982, 1991; White and Rawlins 2016).

Recent developments in the area of question semantics have deepened our understanding of the semantic nature of complement selection, but there still are some open issues. To illustrate, let us first consider the following type-theoretic approach. One of the standard views of question semantics, championed by Karttunen (1977) and others, holds that declarative and interrogative clauses denote different kinds of semantic objects; specifically, declarative clauses denote propositions, while interrogative clauses denote sets of propositions. In this setting, anti-rogative predicates like believe are analyzed as those whose denotations exclusively select for propositions, and rogative predicates like wonder as those whose denotations exclusively select for sets of propositions, as illustrated in (1). Throughout this paper, we write $\hat{\tau}$ for the type of sets of type- $\tau$ objects. ${ }^{1}$

$$
\begin{aligned}
& \text { a. } \llbracket \text { believe } \rrbracket=\lambda p_{\langle s, t\rangle} \cdot \lambda x \cdot \lambda w . \operatorname{believe}_{w}(x, p) \\
& \text { b. } \llbracket \text { wonder } \rrbracket=\lambda Q_{\widehat{\langle s, t\rangle}} \cdot \lambda x . \lambda w . \operatorname{wonder}_{w}(x, Q)
\end{aligned}
$$

This analysis needs to make an extra assumption about responsive predicates, which are compatible with both types of embedded clauses. The most popular take on this is that when responsive predicates combine with an interrogative clause, the meaning of the interrogative clause is converted to a specific proposition that represents an 'answer' to the question (Heim 1994; Dayal 1996; Beck and Rullmann 1999; Spector and Egré 2015). We will put aside for the moment the interesting but complicated issue of what counts as an appropriate answer to a question (see Sect. 4.2), but one issue that arises here is that if any such mechanism that converts sets of propositions to propositions is available, it becomes unclear why anti-rogative predicates cannot combine with interrogative clauses. That is, just as (2a) means roughly 'John doesn't know the true answer to the question Who danced?', (2b) should be able to mean something like 'John doesn't believe the true answer to the question Who danced?'.

\footnotetext{
${ }^{1}$ Since the set of partial functions of type $\langle\sigma, t\rangle$ is not isomorphic to the set of subsets of $D_{\sigma}$, we will explicitly distinguish sets and their characteristic functions.
} 
(2) a. John doesn't know who danced.

b. *John doesn't believe who danced.

Some recent theories of question semantics do not make a type distinction between declarative and interrogative clauses (Ciardelli et al. 2013; Uegaki 2015; Theiler et al. 2018). On these accounts, both declarative and interrogative clauses denote sets of propositions, and the difference between declarative and interrogative clauses boils down to whether or not the denotation is inquisitive (where a clausal meaning is inquisitive if it contains multiple alternatives, i.e., maximum propositions with respect to entailment, and non-inquisitive if it contains only one alternative). In this setting, rogative predicates can be analyzed as those that exclusively select for inquisitive contents, anti-rogative predicates as those that exclusively select for non-inquisitive contents, and responsive predicates as those that are insensitive to inquisitiveness. Concretely, these restrictions could be encoded as sortal presuppositions, as in (3).

$$
\begin{aligned}
& \text { a. } \llbracket \text { believe } \rrbracket=\lambda Q_{\widehat{\langle s, t\rangle}} \cdot \lambda w: \neg \text { inquisitive }(Q) \cdot \lambda x \text {. } \operatorname{believe}_{w}(x, Q) \\
& \text { b. «wonder } \rrbracket=\lambda Q \widehat{\langle s, t\rangle} \cdot \lambda w \text { : inquisitive }(Q) . \lambda x \text {. } \operatorname{wonder}_{w}(x, Q) \\
& \text { c. } \llbracket \text { be certain } \rrbracket=\lambda Q_{\widehat{\langle s, t\rangle}} \cdot \lambda x \cdot \lambda w \cdot \operatorname{certain}_{w}(x, Q)
\end{aligned}
$$

For such a theory to be truly explanatory, however, it needs to be able to predict which predicates have what restrictions, but this turns out to be not at all trivial. For instance, be certain and believe have very similar meanings, but why is it that the former is insensitive to inquisitiveness, while the latter is sensitive to it?

Recently, Theiler et al. (2019) and Mayr (2019) have proposed a partial answer to this question. As originally noticed by Zuber (1982), neg-raising predicates are generally anti-rogative (e.g. believe, think, expect, assume, presume, reckon, advisable, desirable, likely). To explain this generalization, Theiler et al. (2019) and Mayr (2019) put forward semantic accounts according to which such predicates give rise to logically trivial interpretations with interrogative complements, due to their negraising property. We do not go into the details of these accounts here, but we think such semantic explanations are conceptually attractive, as they reduce the selectional properties of these predicates to an independently observed semantic property.

One limitation of these accounts, however, is that they only explain a subset of antirogative predicates. That is, while neg-raising predicates seem to be all anti-rogative, not all anti-rogative predicates are neg-raising. Concretely, predicates like hope, wish, fear, deny, and regret are not neg-raising but are still anti-rogative.

Thus, while there is a conceptual advantage in explaining anti-rogativity in semantic terms, such explanations are not applicable to all anti-rogative predicates. This of course does not mean that these accounts should be dismissed altogether. Rather, we think it is plausible that different anti-rogative predicates are anti-rogative for different semantic reasons. In this paper, we will develop a semantic analysis of the anti-rogativity of non-veridical preferential predicates like hope. If successful, it will complement the aforementioned analyses of the anti-rogativity of neg-raising predicates.

To be clear, we will only attempt to explain the selectional properties of predicates like hope that show the following properties: their semantics is preferential/order- 
based and semantically focus sensitive (see Sect. 2 for details). For the rest of this paper, we will call predicates that show these semantic properties simply preferential predicates. As a consequence, there will still be some anti-rogative predicates that are unaccounted for both by theories of neg-raising predicates and by our theory, such as regret and deny. We believe their anti-rogativity requires yet another explanation. ${ }^{2}$

The idea we will pursue is similar in nature to the aforementioned accounts of negraising predicates: preferential predicates like hope are prohibited from combining with interrogative clauses because such combinations are bound to result in trivial meanings. We will furthermore show that this analysis also accounts for the fact that their veridical counterparts, like be happy, are responsive. ${ }^{3}$ More generally, our analysis is intended to derive the following empirical hypothesis regarding the relationship between the lexical semantics of clause-embedding predicates and their selectional restrictions:

Hypothesis: All non-veridical preferential predicates are anti-rogative.

At this point, the scope of the current paper should be made explicit. Our goal is to make observations based on a number of English predicates that align with the hypothesis in (4) and to formulate an explicit semantic analysis of the selectional restriction that derives it. It is beyond the scope of this paper to evaluate the hypothesis with respect to the entire English lexicon, let alone with respect to lexicons cross-linguistically. This said, we submit that formulating such a semantic analysis has substantial empirical and theoretical implications. For one, (4) makes testable empirical predictions about the selectional restrictions of prototypically preferential predicates that are nonveridical, such as hope, prefer, and fear. The predictions are falsifiable and empirically supported, as we will claim. Furthermore, these predicates are not accounted for by previous analyses. Also, our hypothesis, if correct, contributes to the existing literature by providing another empirical domain in which the theoretical notion of preferential predicates is useful, alongside monotonicity (Heim 1992), mood selection (Villalta 2008), interpretation of epistemic modals in the complement (Anand and Hacquard 2013), incompatibility with whether-questions (Romero 2015), etc.

The structure of the present paper is as follows. In Sect. 2 we will present our main empirical observation that non-veridical preferential predicates are anti-rogative while their veridical counterparts are responsive. We will also be explicit about what predicates fall into the scope of our analysis and what predicates don't. In Sect. 3, we will develop our core account, which we will refine in Sect. 4. Sect. 5 is devoted to discussion of the role of prepositions, most notably about, in the present phenomenon. Sect. 6 concludes.

\footnotetext{
2 As a reviewer has pointed out to us, the anti-rogativity of regret might not be cross-linguistically stable, as the German bedauern 'regret' seems to accept interrogative complements, as pointed out by Schwabe and Fittler (2009) and Grohne (2017). If regret and bedauern have the same relevant lexical-semantic properties, the pair would provide an argument against an explanation for their selectional restrictions that is solely based on the lexical semantics of the predicates. This is left for future work.

3 We say that a clause-embedding predicate $V$ is veridical if $\ulcorner\alpha V$ s that $p\urcorner$ entails $p$. Factivity is a special case of veridicality. An embedding predicate $V$ is factive if $\ulcorner\alpha V$ s that $p\urcorner$ presupposes $p$.
} 


\section{Preferential predicates and their selectional properties}

Following previous studies on the typology of attitude predicates (Anand and Hacquard 2013; Bolinger 1968; Heim 1992; Villalta 2008; Rubinstein 2012; Harner 2016, among others), we recognize a class of attitude predicates that are focus sensitive and express comparative meanings about focus alternatives, which we simply call preferential predicates in this paper. They include desideratives (e.g. hope, wish, want, fear, be surprised, be happy) and directives (e.g. demand, advise, encourage). Our main observations at this point are based on the following predicates:
a. Non-veridical preferential predicates:
hope, wish, expect, want, be eager, aspire, fear, desire, prefer
b. Veridical preferential predicates:
be surprised, be annoyed, be glad, be happy, like, love, hate

All of these predicates are compatible with declarative complements, as in (6).

(6) a. Ben hopes/wishes that Becky is invited to the party.

b. Chris expects/fears that Cathy is invited to the party.

c. Dorothy is surprised/annoyed/glad/happy that Daniel will give a presentation.

Among these, the ones that are veridical/factive with declarative complements are responsive and are compatible with interrogative complements, as in (7). ${ }^{4}$

(7) a. Andy is surprised (at/by) which students are invited to the party.

b. Ben is happy/glad ?(about) which students are invited to the party.

c. Chris liked/hated which students were invited to the party.

The non-veridical ones, on the other hand, are anti-rogative, and incompatible with interrogative complements.

(8) a. *Ben hopes/wishes which students will be invited to the party.

b. *Chris expects/fears how many students will be invited to the party.

Note here that the which-NP clauses in the above examples cannot have a free-relative interpretation (Huddleston and Pullum 2002: 398). That these predicates can embed genuine interrogative complements (as opposed to free relatives) can be further confirmed by checking the compatibility with wh-else (Ross 1967: 38), which also cannot be interpreted as a free relative.

(9) a. Andy is surprised (at/by) who else is invited to the party.

b. Ben is glad/happy ?(about) who else is invited to the party.

c. Chris liked/hated who else was invited to the party.

The contrast between veridical and non-veridical preferential predicates with respect to interrogative complements, as illustrated in the above examples, is the

\footnotetext{
4 Some of these cases sound better with a preposition like about, but we should be careful as about itself might make an interrogative complement available. This issue will be taken up in Sect. 5 .
} 
empirical focus of the current paper. However, it should be noted that not all types of interrogative complements are compatible with veridical preferential predicates, as previously observed (Karttunen 1977). That is, they are incompatible with whethercomplements:

a. *Andy is surprised (at/by) whether Alice is invited to the party.

b. *Ben is glad/happy (about) whether Becky is invited to the party.

c. *Chris liked/hated whether Cathy was invited to the party.

We assume that the pattern exemplified in (10) receives an explanation independent from our analysis of the anti-rogativity of non-veridical preferentials. In particular, our final analysis of preferential predicates presented in Sect. 3.4 below is compatible with Romero's (2015) account of the incompatibility between preferential predicates and whether-complements. For other existing accounts of the same puzzle, see e.g. d'Avis (2002), Abels (2004), Guerzoni (2007), Sæbø (2007), Nicolae (2013), Roelofsen et al. (2019), and Roelofsen (2019).

All in all, the data presented above corroborate our hypothesis that non-veridical preferential predicates are anti-rogative and their veridical/factive counterparts are responsive. Before moving on to our analysis, several further remarks are in order.

\subsection{Focus sensitivity}

Firstly, we would like to stress that our empirical generalization is meant to be limited to what we call preferential predicates, which have preference-based semantics and are focus sensitive in the semantic sense. Admittedly, whether a given predicate has preference-based meaning is not always pre-theoretically clear (cf. Portner and Rubinstein 2012). On the other hand, focus sensitivity is a very useful criterion for our purposes. That is, as many authors have noted (Villalta 2008; Rubinstein 2012; Romero 2015; Harner 2016), the attitude predicates in question change truth conditions based on the focus structure of the embedded sentence. Here's an example illustrating this (modeled after Romero 2015, (13)):

(11) CONTEXT: Natasha does not like to teach logic and prefers to teach syntax. She is not allowed to teach both. This year, it is likely that she needs to teach logic, and if so, she prefers to do so in the morning, as she prefers to do all her teaching in the morning.

a. Natasha hopes that she'll teach logic in the MORning.

TRUE

b. Natasha hopes that she'll teach LOgic in the morning.

FALSE

Similarly, Romero (2015) provides the following example for surprise:

(12) CONTEXT: Lisa knew that syntax was going to be taught. She expected syntax to be taught by John, since he is the best syntactician around. Also, she expected syntax to be taught on Mondays, since that is the rule.

a. It surprised Lisa that John taught syntax on TUESdays.

TRUE

b. It surprised Lisa that JOHN taught syntax on Tuesdays.

FALSE 
These observations led the authors cited above to postulate semantics for preferential predicates that compare the focus alternatives determined by the focus structure of the embedded sentence. We will discuss a particular version of this idea due to Romero (2015) in the next section.

It is important to note that these predicates exhibit truth-conditional effects of focus, not just pragmatic effects of focus, which presumably all predicates exhibit one way or another (see Harner 2016 for more discussion on this). For instance, a preference-based analysis for decide that compares different alternatives might appear promising. ${ }^{5}$ If decide is a preferential predicate, it will be a counter-example to our generalization, because it is not veridical but is responsive.

a. Natasha decided that she'll go to LONdon this summer.

b. Natasha decided where she'll go this summer.

The idea is that decide in (13a) compares different places Natasha could go to this summer.

However, according to our definition of preferential predicates, decide doesn't count as one, because it does not seem to trigger truth-conditional effects of focus. Concretely, consider the following example.

(14) CONTEXT: Natasha is required to teach logic, but she's free to choose when to teach it. However, if she teaches anything in the morning, it needs to be logic. In the end, she decides to teach logic in the morning and syntax in the afternoon.

a. Natasha decided that she'll teach logic in the MORning.

TRUE

b. Natasha decided that she'll teach LOgic in the morning.

?TRUE

Crucially, in this context it is not up to Natasha to decide what to teach if she teaches in the morning. If decide were truth-conditionally focus sensitive, (14b) should be false, but it does not seem to be. Rather, it's true yet infelicitous (which is presumably the pragmatic effect of focus here).

Our account below will crucially rely on truth-conditional focus sensitivity. Therefore, predicates like decide simply fall outside of our analysis here.

\subsection{Infinitival complements}

Our second remark concerns infinitival complements. Many preferential predicates take infinitival complements, in addition to finite ones (some, such as want, be eager, and aspire, are in fact more natural with infinitival complements than with finite ones). As expected from our hypothesis, non-veridical preferential predicates that are compatible with infinitival complements are only compatible with declarative (non$w h)$ ones and not with interrogative $(w h)$ ones, as shown in the following examples.

\footnotetext{
5 We thank a reviewer for directing our attention to decide.
} 
(15) a. Alice prefers to invite Andrew to the party.

b. Ben hopes/wishes to invite Becky to the party.

c. Chris wants/is eager to invite Cathy to the party.

a. *Alice prefers (about) who to invite to the party.

b. *Ben hopes/wishes (about) who to invite to the party.

c. *Chris wants/is eager (about) who to invite to the party.

What is unexpected, however, is that veridical preferential predicates that are compatible with infinitival complements are also only compatible with declarative ones, as illustrated in (17).
a. *Alice is surprised (at/by) (about) who to invite to the party.
b. *Ben is glad/happy (about) who to invite to the party.
c. ${ }^{*}$ Chris liked/hated (about) who to invite to the party.

Our analysis will focus on finite complements, and will not have much to say about infinitival complements. However, it will only entail that non-veridical preferential predicates cannot take interrogative complements; it remains compatible with the possibility that the partial anti-rogativity of veridical preferential predicates with infinitival complements observed here is due to some other, yet unknown reason, which is in line with our general idea that anti-rogativity may arise from several different factors.

\subsection{Say}

Thirdly, a reviewer asks a related question about the predicate say. They wonder if say with an infinitival complement, which seems to have directive focus-sensitive semantics, is a counterexample to our generalization, as it is non-veridical but responsive.

a. John said to leave at SIX.

b. John said when to leave.

But it is not evident that the directive meaning is coming from the embedding predicate say here. That is, say indeed expresses directive meaning when combined with an infinitival complement, but not when combined with a finite complement. Rather, to paraphrase the directive meaning of (18) with a finite complement, a separate modal like should is required.

a. John said that we should leave at six.

b. John said when we should leave.

We think it would be desirable to maintain the same semantics of the predicate say with both finite and infinitival complements. If so, at least part of the directive meaning of (18) should be attributed to the modality of the infinitival clause. It follows that say itself does not encode directive meaning and consequently is outside the scope of our generalization. 


\section{Why veridicality matters for preferential predicates}

In this section we will spell out our explanation as to why non-veridical preferential predicates are anti-rogative while veridical ones may be responsive. The core idea is that non-veridical preferential predicates with interrogative clauses give rise to trivial meaning while veridical preferential predicates do not, regardless of the complement clause type. We will formalize this using (i) a uniform approach to clause embedding (Ciardelli et al. 2013; Uegaki 2015; Theiler et al. 2018) (Sect. 3.1) and (ii) a degreebased semantics for preferentials (Romero 2015) (Sect. 3.2).

Our analysis will crucially rely on the lexical denotations of clause-embedding predicates. It is important therefore to make explicit a certain methodological principle which we follow in determining lexical denotations of specific clause-embedding predicates. The principle goes as follows:

\section{Posit only observable lexical-semantic variation:}

For any pair of predicates $V$ and $V^{\prime}$ we posit lexical-semantic variation between $V$ and $V^{\prime}$ only if this lexical-semantic variation can be motivated by the truth conditions of acceptable sentences $\ulcorner x V \operatorname{s} \varphi\urcorner$ and $\left\ulcorner x V^{\prime} \operatorname{s} \varphi\right\urcorner$, where $x$ is a DP and $\varphi$ is a clausal complement.

In other words, once we conclude that $V$ and $V^{\prime}$ have certain lexical denotations based on observations about the truth conditions of (acceptable) sentences with a certain clause type (e.g., a declarative complement), the denotations will not be revised based on a further observation that $V$ and $V^{\prime}$ differ in their compatibility with another clause type (e.g., an interrogative complement). The rationale behind this principle is to ensure that our account of selectional restrictions with respect to a certain clause type is explanatory in the sense that it is based on independently motivated lexical semantics. Below, when making theoretical decisions about lexical denotations, we will refer back to this principle.

\subsection{A uniform approach to clausal embedding}

We follow Ciardelli et al. (2013), Uegaki (2015), Theiler et al. (2018) and take a uniform approach to clause embedding where both declarative and interrogative complements denote sets of propositions and all clause-embedding predicates take sets of propositions as arguments. We assume that declarative sentences denote singleton sets of propositions, while interrogative clauses denote non-singleton sets of propositions. ${ }^{6}$ (See Sect. 4.2 for the treatment of exhaustivity in embedded questions.)

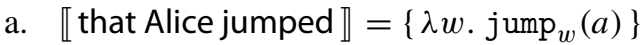

$$
\begin{aligned}
& \text { b. } \llbracket \text { whether Alice jumped } \rrbracket=\left\{\lambda w \cdot \operatorname{jump}_{w}(a), \lambda w . \neg \operatorname{jump}_{w}(a)\right\} \\
& \text { c. } \llbracket \text { who jumped } \rrbracket=\left\{\lambda w . \operatorname{jump}_{w}(x) \mid x \in D\right\} \cup\left\{\lambda w . \neg \exists x\left[\operatorname{jump}_{w}(x)\right]\right\}
\end{aligned}
$$

\footnotetext{
6 We could include all non-trivial stronger propositions in the denotations, as in certain versions of Inquisitive Semantics, but such structure is unnecessary for the purposes of this paper.
} 
We assume that a declarative complementizer converts a proposition into a singleton set containing the proposition. ${ }^{7}$

In this setting, representational predicates like be certain and know have an existential semantics, as in (22).

$$
\begin{aligned}
& \text { a. } \llbracket \text { be certain } \rrbracket=\lambda Q_{\widehat{\langle s, t\rangle}} \cdot \lambda x \cdot \lambda w . \exists p \in Q\left[\operatorname{certain}_{w}(x, p)\right] \\
& \text { b. } \llbracket \text { know } \rrbracket=\lambda Q_{\widehat{\langle s, t\rangle}} \cdot \lambda x . \lambda w: \exists p \in Q[p(w)] . \exists p \in Q[p(w) \wedge \\
& \left.\operatorname{know}_{w}(x, p)\right]
\end{aligned}
$$

All clause-embedding predicates take a set of propositions, so they are all typecompatible with both interrogative and declarative complements. For instance, the denotation of believe is of the same type as that of know:

$$
\llbracket \text { believe } \rrbracket=\lambda Q_{\widehat{\langle s, t\rangle}} \cdot \lambda x \cdot \lambda w . \exists p \in Q\left[\operatorname{believe}_{w}(x, p)\right]
$$

Following the methodological principle in (20), we do not posit any lexical semantic variation between be certain and believe beyond what is observable from their behaviors with declarative complements. In particular, both be certain and believe involve existential quantification over propositions because (a) we have analyzed be certain as having an existential semantics, given the truth conditions with interrogative complements, and (b) the truth conditions of be certain and believe with declarative complements do not motivate variation in the quantificational force between the two predicates. The anti-rogativity of believe, therefore, needs to be explained by other means than type incompatibility. As mentioned before, see Theiler et al. (2019) and Mayr (2019) for proposals to reduce it to its neg-raising property.

\subsection{Degree-based semantics for preferential predicates}

To analyze preferential predicates, we follow Romero's (2015) degree-based semantics, which in turn is based on Villalta's (2008) analysis. As will be discussed later, this degree-based semantics offers an attractive account of the anti-rogativity of non-veridical preferential predicates, involving a reasonable assumption about the semantics of degree constructions in general.

As noted above in Sect. 2.1, preferential predicates show truth-conditional focus sensitivity, which led previous authors to propose that these predicates compare focus alternatives determined by the focus structure of the embedded clause. The degreebased semantics for preferential predicates by Romero (2015) builds on this insight, and treats the focus structure of the complement as providing the comparison class against which the subject's preferences are compared. Concretely, assuming the Roothian alternative semantics for focus (Rooth 1992), the context is assumed to provide a set of alternatives $C$, which preferential predicates refer to. ${ }^{8}$ For example, the seman-

\footnotetext{
7 We could alternatively assume throughout a system akin to Hamblin Semantics, where all denotations are sets (Hamblin 1973; Kratzer and Shimoyama 2002).

8 We assume for the sake of exposition that focus association with preferential predicates is conventional (in the sense of Beaver and Clark 2008), but nothing crucial hinges on this. See Romero (2015) for discussion. Also, to avoid clutter, we conflate variables in the object language and meta-language.
} 
tics for be happy looks like (24), where Pref is a degree function defined in (25) and $\theta(C)$ is the threshold degree given the comparison set $C .{ }^{9}$ We will have more to say on the threshold function $\theta$ below.

$$
\begin{aligned}
& \llbracket \text { be happy }_{C} \rrbracket^{w}=\lambda p_{\langle s, t\rangle} \cdot \lambda x . \lambda w: p(w) \wedge \operatorname{believe}_{w}(x, p) \wedge p \in C . \\
& \operatorname{Pref}_{w}(x, p)>\theta(C)
\end{aligned}
$$

a. $\operatorname{Pref}_{w}(x, p):=$ the maximum degree to which $x$ prefers $p$ at $w$

b. $\theta(C):=$ the standard threshold given the comparison class $C$

In prose: $x$ is happy that $p$ presupposes that $p$ is true, that $x$ believes that $p$, and that $p$ is a member of the focus alternatives $C$, and asserts that the degree to which $x$ prefers $p$ at $w$ is greater than the threshold given $C$. As Romero (2015) argues, the last presupposition-that $p \in C$-is an instance of a presupposition existing in degree constructions in general, namely that the comparison class includes the comparison term.

Note that (24) assumes that be happy semantically selects for a single proposition. To reformulate the analysis to fit the uniform approach to clausal embedding introduced in the previous section, we make the predicate select for a set of propositions and relate the subject and the set using (25) via existential quantification: ${ }^{10}$

$$
\begin{gathered}
\llbracket \text { be happy } \rrbracket^{w}=\lambda Q_{\widehat{\langle s, t\rangle}} . \lambda x \cdot \lambda w: \exists p \in Q\left[p(w) \wedge \operatorname{believe}_{w}(x, p) \wedge p \in C\right] . \\
\exists p^{\prime \prime} \in Q\left[\begin{array}{c}
p^{\prime \prime}(w) \wedge \operatorname{believe}_{w}\left(x, p^{\prime \prime}\right) \wedge p^{\prime \prime} \in C \wedge \\
\operatorname{Pref}_{w}\left(x, p^{\prime \prime}\right)>\theta(C)
\end{array}\right]
\end{gathered}
$$

Let us see how (26) works with concrete interrogative and declarative complements. First, following Beck (2006), we take $w h$-items to be necessarily focused. Given this, in our semantics the focus semantic value of a wh-complement turns out to be equivalent to its ordinary semantic value, as in (27). ${ }^{11}$ Letting $\mathcal{Q}$ be the focus/ordinary semantic value of the interrogative complement, be happy with an interrogative complement can be analyzed as in (28):

$$
\mathcal{Q}:=\llbracket \text { who jumped } \rrbracket^{o}=\llbracket \text { who }_{F} \text { jumped } \rrbracket^{f}
$$

\footnotetext{
9 The formulation in (24) uses a measure function Pref that maps individual-proposition pairs to degrees rather than to relations between degrees and individuals/propositions as done in Romero (2015). This is only for presentational reasons (the former formulation results in shorter formulae); nothing crucial hinges on this choice.

10 In (26), to avoid the 'binding problem' concerning the existential quantifications in the presupposition and the assertion, the content of the presupposition is repeated in the scope of the existential quantification in the assertion. See Spector and Egré (2015) for a similar solution to the binding problem in the domain of question embedding.

11 As pointed out to us by Henriëtte de Swart (p.c.), this equivalence might not hold when number morphology is involved. Concretely, while 【 which student \ ranges over singular individuals, its focus value $\llbracket$ which student $\rrbracket^{f}$ might include plural individuals, in which case the ordinary semantic value will be a subset of the focus semantic value. As far as we can see, however, there is no empirical reason to assume that $\llbracket$ which student $\rrbracket^{f}$ contains plural individuals. Technically, we could exclude plural individuals by assuming a type distinction between singular and plural individuals, such that singular individuals are type $e$ while plural individuals are type $\widehat{e}$. See footnote 17 for another technical way of excluding plural individuals from the focus value.
} 


$$
\begin{aligned}
& \llbracket \text { John is happy }{ }_{C} \text { (about) }\left[\text { who }_{F} \text { jumped }\right] \sim C \rrbracket^{o} \\
& =\lambda w: \exists p \in \mathcal{Q}\left[\begin{array}{l}
p(w) \wedge p \\
\wedge \operatorname{believe}_{w}(j, p)
\end{array}\right] \\
& \exists p^{\prime \prime} \in \mathcal{Q}\left[\begin{array}{l}
p^{\prime \prime}(w) \wedge \operatorname{believe}_{w}\left(j, p^{\prime \prime}\right) \wedge p^{\prime \prime} \in C \\
\wedge \operatorname{Pref}_{w}\left(j, p^{\prime \prime}\right)>\theta(C)
\end{array}\right]
\end{aligned}
$$

Given the definition of the $\sim$-operator in (29) (Romero 2015, cf. Rooth 1992), $C$ in (28) is constrained as in (30).

$$
\begin{aligned}
& \llbracket \alpha \sim C \rrbracket^{o} \text { is defined only if } C \subseteq \llbracket \alpha \rrbracket^{f} \text {; if defined, } \llbracket \alpha \sim C \rrbracket^{o}=\llbracket \alpha \rrbracket^{o} \\
& C \subseteq \llbracket \text { who jumped } \rrbracket^{f}=\mathcal{Q}
\end{aligned}
$$

All in all, (28) presupposes that there is a true answer of $\mathcal{Q}$ which John believes, and asserts that a true answer of $\mathcal{Q}$ which John believes is such that he prefers it to a greater extent than the standard threshold given the alternatives in $C$, which in turn is a subset of $\mathcal{Q}$.

Next, a declarative-embedding sentence would be analyzed as in (31), with the variable $C$ constrained by the focus structure as in (32). Here, we let $A:=$ $\lambda w \cdot \operatorname{jumped}_{w}(a)$.

$$
\begin{aligned}
& \left.\llbracket \text { John is happy }_{C}{\text { that }\left[\text { Alice }_{F} \text { jumped }\right] \sim C \rrbracket^{o}}^{o} \begin{array}{c}
p(w) \wedge p \in C \\
\wedge \operatorname{believe}_{w}(j, p)
\end{array}\right] . \\
& \qquad \exists p^{\prime \prime} \in\{A\}\left[\begin{array}{c}
p^{\prime \prime}(w) \wedge \operatorname{believe}_{w}\left(j, p^{\prime \prime}\right) \wedge p^{\prime \prime} \in C \wedge \\
\operatorname{Pref}_{w}\left(j, p^{\prime \prime}\right)>\theta(C)
\end{array}\right] \\
& =\lambda w: A(w) \wedge A \in C \wedge \operatorname{believe}_{w}(j, A) . \\
& A(w) \wedge \operatorname{believe}_{w}(j, A) \wedge A \in C \wedge \operatorname{Pref}_{w}(j, A)>\theta(C) \\
& C \subseteq \llbracket \text { that }[\text { Alice }]_{F} \text { jumped } \rrbracket^{f}=\mathcal{Q}
\end{aligned}
$$

That is, (31) presupposes that Alice jumped and that John believes that Alice jumped, and asserts that John prefers Alice's jumping to a greater extent than the threshold given the alternatives in $C$, which again is constrained by $\mathcal{Q}$.

Thus, the degree-based analysis provides a straightforward account of both declarative and interrogative complementation under veridical preferential predicates. Romero (2015) shows that the degree-based analysis enables an attractive account of two puzzles concerning veridical preferential predicates: (i) incompatibility with whether-complements ${ }^{12}$ and (ii) (typical) incompatibility with strongly-exhaustive embedded questions. Another virtue of the degree-based analysis is that (with suitable assumptions) it can account for the behavior of preferential predicates as gradable predicates, as in their occurrence in comparatives, e.g. (33).

a. Chris is happier that Alice jumped than Bill is.

b. Chris liked/hated that Alice jumped more than Bill did.

\footnotetext{
12 More precisely, Romero's (2015) analysis enables an account of the incompatibility of preferentials with alternative-question whether-complements. To account for their incompatibility with polar-question whether-complements, Romero has to make additional assumptions, e.g. that polar questions involve an elliptical or not and thus are structurally equivalent to alternative questions.
} 


\subsection{The semantics of non-veridical preferential predicates}

Building on the semantics for veridical preferentials in the previous section, we propose the following semantics for a non-veridical preferential, such as hope:

$$
\begin{aligned}
& \llbracket \operatorname{hope}_{C} \rrbracket^{o}=\lambda Q_{\widehat{\langle s, t\rangle}} \cdot \lambda x \cdot \lambda w: \exists p \in Q[p \in C] . \exists p^{\prime \prime} \in Q\left[p^{\prime \prime} \in C \wedge\right. \\
& \left.\operatorname{Pref}_{w}\left(x, p^{\prime \prime}\right)>\theta(C)\right]
\end{aligned}
$$

In contrast to the veridical preferential be happy in (26), which requires that the preferred answer is true and is believed by the subject, the non-veridical preferential hope in (34) lacks such requirements. The body of the function simply states that there is an answer (which is also a member of $C$ ) that the subject prefers to a greater extent than the threshold given $C$. Again, following the methodological principle in (20), we do not posit any lexical semantic variation between veridical and non-veridical preferential predicates beyond what is observable in their behavior with declarative complements. This is why we analyze hope as involving an existential quantification over propositions in (34).

With a declarative complement, (34) derives the meaning that the subject prefers the proposition denoted by the complement to a greater degree than the threshold given focus alternatives. Here is a concrete example. Again, let $A:=\lambda w$. jumped $(a)$.

$$
\begin{aligned}
& \llbracket \text { John hopes } \\
& C \text { that }\left[\text { Alice }_{F} \text { jumped }\right] \sim C \rrbracket^{w}=\lambda w: A \in C . \operatorname{Pref}_{w}(j, A)> \\
& \theta(C)
\end{aligned}
$$

On the other hand, the meaning predicted for (34) with an interrogative complement, exemplified in (36), turns out to be systematically trivial, assuming an additional presupposition triggered by the preferential predicate, which is the underlined portion of the presupposition — what we call Threshold Significance. (As Threshold Significance is a presupposition triggered by preferential predicates in general, the lexical entry for be happy in (26) must also be revised to include this presupposition.)

$$
\begin{aligned}
& \left.\llbracket \text { John hopes }{ }_{C} \text { [who }_{F} \text { jumped }\right] \sim C \rrbracket^{o} \\
& =\lambda w: \exists p \in \mathcal{Q}[p \in C] \wedge \exists d \in\left\{\operatorname{Pref}_{w}(j, p) \mid p \in C\right\}[d>\theta(C)] . \exists p^{\prime \prime} \in \\
& \mathcal{Q}\left[p^{\prime \prime} \in C \wedge \operatorname{Pref}_{w}\left(j, p^{\prime \prime}\right)>\theta(C)\right]
\end{aligned}
$$

Threshold Significance requires that there be an element in the comparison class whose degree along the relevant scale is higher than the threshold returned by $\theta$. We take this to be a general property of gradable expressions whose interpretations depend on a threshold, including the positive form of gradable adjectives like tall and preferential predicates like hope. We will give an empirical and conceptual motivation for (36) in Sect. 3.5, but let us first illustrate how (36) derives a logically trivial meaning, which in turn leads to ungrammaticality, following Gajewski (2002).

\subsection{Deriving the anti-rogativity of non-veridical preferentials}

The gist of our analysis of the anti-rogativity of non-veridical preferentials goes as follows. Given Threshold Significance, (36) turns out to be necessarily true whenever 
it is defined. This is so since whenever Threshold Significance holds, there is always a proposition in $C \subseteq \mathcal{Q}$ which John prefers more than the threshold given $C$. We follow Barwise and Cooper (1981), Gajewski (2002), and Chierchia (2013) in assuming that systematic logical triviality leads to ungrammaticality. Hence, the logical triviality of (36) accounts for its ungrammaticality. On the other hand, hope with a declarative complement, as in (35), is not logically trivial, regardless of Threshold Significance. This is so because whether the assertion of (35) is true depends on whether or not John prefers the particular proposition mentioned in the declarative complement (i.e., that Alice jumped), and Threshold Significance does not guarantee that he does. This explains the anti-rogativity of non-veridical preferential predicates like hope.

Moving on to veridical preferentials, we note that they do not induce logical triviality regardless of the complement clause type, due to the veridical restriction on existential quantification. The assertion of be happy with an interrogative complement in (28) above is non-trivial (regardless of Threshold Significance) since its truth is contingent on whether John prefers a true answer. That is, even when Threshold Significance is met, the assertion of (28) can be false if John prefers a false answer rather than a true answer. Also, similarly to the non-veridical case, be happy with a declarative complement as in (31) is non-trivial because the quantification over answers has a singleton domain. Whether (31) is true depends on whether John prefers the particular proposition that is in the ordinary semantic value of the declarative complement.

Regarding the precise relationship between logical triviality and ungrammaticality, we assume the following principles from Gajewski (2002), where (37a) is modified from the original to encompass presuppositional denotations.

a. An LF constituent $a$ of type $t$ is L-ANALYTIC iff $a$ 's logical skeleton receives the same truth-value under every variable assignment where the denotation is defined.

b. A sentence is ungrammatical if its Logical Form contains an L-analytic constituent.

Here, we also need the definition of logical skeletons, in which all non-logical vocabularies are represented as variables. Defining logical vocabularies in general is beyond the scope of this paper; we will simply assume that the logical skeletons of sentences with a matrix predicate embedding a clausal complement look as follows:
a. $\left[\alpha\left[\operatorname{vp} \operatorname{pred}_{\Gamma}\left[\mathrm{CP} \varphi\left[\beta_{F}\right]\right] \sim \Gamma\right]\right]$
(declarative complementation)
b. $\left[\alpha\left[\operatorname{vp} \operatorname{pred}_{\Gamma}\left[\mathrm{CP} Q \varphi\left[\mathrm{wh}_{F}\right]\right] \sim \Gamma\right]\right]$
(interrogative complementation)

Here, all Greek letters — $\alpha$ (the subject), $\Gamma$ (the comparison class), $\varphi$ (the complement), and $\beta$ (the focused item) - are variables, while all other items_-pred, $\mathrm{Q}$, wh, and the operator $\sim$-are logical vocabularies. ${ }^{13}$ Also, we assume that a logical skeleton represents a focus structure, and $\varphi\left[\beta_{F}\right]$ indicates that $\varphi$ contains an occurrence of $\beta$

\footnotetext{
13 A potential problem here is that there is no known definition of 'logical vocabularies' under which hope is categorized as one. Following van Benthem (1989), Gajewski (2002) defines logical vocabularies in terms of permutation invariance, but our denotation of hope does not satisfy this criterion, as it depends on, e.g., the world of evaluation. In this paper, we do not attempt to offer a definition of logical vocabularies under which hope and other attitude predicates can be categorized as logical (see Abrusán 2019 for a recent review on the issue of delineating the boundary between logical and non-logical vocabularies in general).
} 
as a focus. The operator $\mathrm{Q}$ in $(38 \mathrm{~b})$ is the interrogative operator, which will be defined in Sect. 4.1.

According to the definition in (37a), the declarative version of the logical skeleton, i.e. (38a), is not L-analytic, regardless of whether the embedding preferential predicate pred is veridical or non-veridical. This is so since the truth of the LF depends on whether $\alpha$ 's referent prefers the specific proposition mentioned in $\varphi$. On the other hand, the interrogative version of the logical skeleton, (38b), is L-analytic if pred is a non-veridical preferential predicate (e.g. hope) with Threshold Significance. If the truth value of (38b) is defined, i.e., if its presupposition-in particular Threshold Significance-is met, (38b) is always true regardless of the assignments for the free variables. This is so since the semantics of a non-veridical preferential pred is such that it returns true whenever there is a proposition in the comparison class that exceeds the threshold.

Before concluding this section, we would like to comment on Anand and Hacquard's (2013) proposal that the lexical semantics of emotive doxastics (a subtype of non-veridical preferentials) such as hope and fear not only involves the preferential component but also the doxastic condition that the subject considers the prejacent possible. Prima facie, this proposal might appear incompatible with our analysis since the doxastic condition can be seen as providing a restriction on the existential quantification, just as the veridical restriction does in veridical predicates. However, this is not the case, as the doxastic condition provides a restriction on the comparison class as a whole. That is, we propose the following rendition of our entry for hope to incorporate Anand and Hacquard's (2013) doxastic condition (the underlined part corresponds to the doxastic condition):

$$
\begin{aligned}
& \llbracket \operatorname{hope}_{C} \rrbracket^{o}=\lambda Q_{\widehat{\langle s, t\rangle}} \cdot \lambda x \cdot \lambda w: \exists p \in Q[p \in C] \wedge \exists d \in \\
& \left\{\operatorname{Pref}_{w}(x, p) \mid p \in C\right\}[d>\theta(C)] \wedge \forall p^{\prime} \in C\left[D o x_{x}^{w} \cap p^{\prime} \neq \varnothing\right] . \exists p^{\prime \prime} \in \\
& Q\left[p^{\prime \prime} \in C \wedge \operatorname{Pref}_{w}\left(x, p^{\prime \prime}\right)>\theta(C)\right]
\end{aligned}
$$

In this entry, the comparison class $C$ is restricted to those alternatives that are compatible with the subject's beliefs. Threshold Significance then states that there is an element in this restricted domain $C$ that exceeds the subject's standard threshold for preference. Given these presuppositions, the assertion of hope with an interrogative complement remains trivial.

Interpretations of declarative-embedding sentences provide evidence for different ways in which the veridicality of veridical preferential predicates and the doxastic condition of emotive doxastics are encoded. In (40a), John's preference for Alice's jumping is compared to alternative propositions that are false at the evaluation world. In contrast, in (40b), John's preference for Alice's jumping is compared only to those alternatives that he considers possible at the evaluation world.

Footnote 13 continued

Rather, just as in Theiler et al. (2019) and Mayr (2019), our focus is to present an analysis of the selectional restriction of certain clause-embedding predicates in terms of L-analyticity, assuming that these predicates can be categorized as logical vocabularies given a suitable definition. 
a. John is happy that ALICE jumped.

b. John hopes that ALICE jumped.

This suggests that the veridicality of be happy does not place a restriction on the comparison class itself, whereas the doxastic condition of hope does, as in our lexical entry in (39). Thus, the doxastic condition of emotive doxastics proposed by Anand and Hacquard (2013) is compatible with our analysis of their anti-rogativity since the condition restricts the comparison class as a whole. In the rest of the paper, we omit the doxastic condition in our analysis of hope for the sake of simplicity, but it can be added back in without any unwelcome consequences.

\subsection{Motivations for Threshold Significance}

Our explanation of the anti-rogativity of non-veridical preferential predicates makes crucial use of Threshold Significance. In this section, we give empirical and conceptual motivation for Threshold Significance in preferential predicates such as be happy and hope.

Empirical support for Threshold Significance comes from the following kind of example.

(41) (CONTEXT: There is no particular student John wants to sing. John knows which student will sing.)

\#John \{isn't happy about/doesn't like $\}$ which student will sing.

If it were not for Threshold Significance, the sentence in (41) would be true given the context. That is, in the given context, it's not true that John's preference singles out one student, so if it were not for Threshold Significance, the sentence should be judged true. But instead it appears to presuppose the existence of a student that John preferred to sing. ${ }^{14}$

Conceptually, Threshold Significance can be motivated based on how pragmatic considerations affect the choice of the threshold. In particular, Qing and Franke (2014) and Lassiter and Goodman (2017) present a game-theoretic analysis of the semantics of gradable adjectives, where the choice of the threshold is determined by how much it contributes to the communicative utility of using the adjective. From this pragmatic perspective, Threshold Significance is quite natural. Here is why. Suppose we choose

\footnotetext{
14 It is not straightforward to give a parallel empirical argument for Threshold Significance with antirogative predicates like hope. Indeed, the following sentence sounds infelicitous given the context.
}

(i) (CONTEXT: there is no student John wants to sing.)

\#John doesn't hope that ALICE will sing.

However, this might be due to focus. That is, focus induces the presupposition that some alternative is true, which projects through negation (e.g., Tonhauser et al. 2013).

Relatedly, note that our analysis is consistent with the fact that (i) is felicitous with a different focus structure, for example, a broad focus on the entire complement clause. This is so because a different focus structure would induce a different set of alternatives, and thus it is possible for Threshold Significance to be met with respect to that set of alternatives while the situation in (i) holds. For example, Threshold Significance with respect to the broad focus is satisfied if John prefers Alice not to sing, which is compatible with the situation given. 
a threshold such that Threshold Significance is not satisfied. That is, every degree in the comparison class is below the threshold. Choosing such a threshold will be useless for communicative purposes since it does not allow us to draw any distinction in the comparison class. Using a more concrete example, if the threshold for tallness is known to exceed the height of any individual in the comparison class, uttering $x$ is tall is useless since it will always be false. Thus, Threshold Significance can be thought of as a natural consequence of the pragmatic reasoning about thresholds. Qing and Franke (2014) further argue that the consideration about the optimal communicative success drives the semantic conventionalization of a certain threshold within a linguistic community in the long run. According to this view, it is plausible that a general principle like Threshold Significance enters into the semantic convention.

One might think that a predicate like be indifferent (about), exemplified in (42), is a problem for our claim, as it is compatible with a situation as described in (41). ${ }^{15}$

John is indifferent about which student will sing.

However, there is an important difference between predicates like hope and be happy on the one hand and predicates like be indifferent on the other. The former involve comparison of propositions while the latter involves comparison of questions. The fact that be indifferent concerns comparison of questions can be supported by the fact that it is marginal at best with declarative complements:
a.??John is indifferent that Alice will sing.
b. John is indifferent about whether Alice will sing.
c. John is indifferent about who will sing.

Given that be indifferent involves comparison of questions, the focus value relevant for sentences like (42) is a set of questions, rather than a set of propositions. Thus, Threshold Significance in the case of (42) would require that there is a question that John is indifferent about to an extent higher than the threshold. This is compatible with the situation described in (41).

\section{Refining the analysis}

The previous section outlined our analysis of the anti-rogativity of non-veridical preferential predicates. However, this analysis still contains loose ends that must be tightened. Specifically, it has empirical problems concerning the treatment of (i) focused non$w h$-items in an interrogative clause, and (ii) exhaustivity of embedded questions. In this section, we discuss how our analysis can be refined to deal with these problems.

\subsection{Selective focus sensitivity}

The first issue concerns the treatment of focus-semantic values of $w h$-clauses. The analysis in Sect. 3 hinges on the assumption that the focus-semantic value of a whclause is derived from varying the value corresponding to the $w h$-phrase, resulting in a

\footnotetext{
15 We thank an anonymous reviewer for pointing out the relevance of predicates like be indifferent.
} 
set equivalent to the Hamblin-semantic value of the clause. However, the compositional mechanism of focus interpretation assumed in Sect. 3 does not guarantee this. In particular, it predicts that stressed non- $w h$-constituents can also contribute to the focussemantic value of a wh-clause. Romero (2015) uses the following kind of pair to illustrate the fact that this is an undesirable feature:

a. Lisa is happy about when JOHN taught syntax.

b. Lisa is happy about who taught syntax on TUESdays.

The two sentences in (44) are not intuitively equivalent. However, the compositional mechanism of focus interpretation in Sect. 3 predicts them to be equivalent because any focus in the complement is predicted to contribute to its focus-semantic value, regardless of whether it is on a wh-word or not.

Romero (2015) addresses this problem using the mechanism of selective focus binding from Wold (1996). Here, we will present a solution along the same lines. The basic idea is to allow certain focus-sensitive operators to have selective focus sensitivity by indexing each focus-bearing constituent. In the case of $w h$-clauses, we posit a Q(uestion)-operator that must be co-indexed with a wh-element. The overall system then predicts that the focus value relevant for the interpretation of an embedding preferential predicate will be constrained by this requirement on the Q-operator.

In this system, a semantic value is determined with respect to two assignment functions, $g$ and $h$, where $g$ handles the non-focus variables and $h$ handles focus variables. The two assignment functions have disjoint sets of indices as their domains. We will notate the indices for non-focus variables with Arabic numerals and those for focus variables with Roman numerals. Following Beck (2006), ${ }^{16}$ the entries of the basic vocabulary look like the following (where $\llbracket \cdot \rrbracket_{o}^{g, h}$ is the ordinary semantic value with respect to the assignments $g$ and $h$, and $\llbracket \cdot \rrbracket_{f}^{g, h}$ is the focus semantic value with respect to these assignments): ${ }^{17}$
a. $\llbracket J o h n \rrbracket_{o}^{g, h}=j$
b. $\llbracket$ John $\rrbracket_{f}^{g, h}=j$
a. $\llbracket \mathrm{JOHN}_{i} \rrbracket_{o}^{g, h}=j$
b. $\llbracket \mathrm{JOHN}_{i} \rrbracket_{f}^{g, h}=h(i)$
a. 【jumped $\rrbracket_{o}^{g, h}=\lambda x \lambda w \cdot \operatorname{jumped}_{w}(x)$
b. $\quad$ jumped $\rrbracket_{f}^{g, h}=\lambda x \lambda w \cdot \operatorname{jumped}_{w}(x)$

\footnotetext{
16 Unlike Beck (2006) and following Wold (1996) and Romero (2015), we assume that the -operator is indexed and allows selective binding.

17 For which-NPs, we assume the following syncategorematic definitions:
}

$\begin{array}{ll}\text { (i) } & \llbracket \text { which }_{i} \mathrm{NP} \rrbracket_{o}^{g, h}=\text { undefined } \\ \text { b. } & \llbracket \text { which } \\ & \mathrm{NP} \rrbracket_{f}^{g, h}=h(i) \text { if } h(i) \in \llbracket \mathrm{NP} \rrbracket_{o}^{g, h} \text {; otherwise undefined. }\end{array}$

This treatment forces the focus value of which student to exclude plural individuals (see footnote 11). 

a. $\llbracket \mathrm{who}_{i} \rrbracket_{o}^{g, h}=$ undefined
b. $\llbracket \mathrm{who}_{i} \rrbracket_{f}^{g, h}=h(i)$
a. $\llbracket \mathrm{Q}_{i} \varphi \rrbracket_{o}^{g, h}=\left\{\llbracket \varphi \rrbracket^{g, h[x / i]} \mid x \in D_{e}\right\}$
b. $\llbracket \mathrm{Q}_{i} \varphi \rrbracket_{f}^{g, h}=\llbracket \mathrm{Q}_{i} \varphi \rrbracket_{o}^{g, h}$

a. $\llbracket \alpha \sim_{i} C \rrbracket_{o}^{g, h}$ is defined only if $g(C) \subseteq\left\{\llbracket \alpha \rrbracket_{f}^{g, h[x / i]} \mid x \in D_{e}\right\}$; if defined, $\llbracket \alpha \sim_{i} C \rrbracket_{o}^{g, h}=\llbracket \alpha \rrbracket_{o}^{g, h}$

b. $\llbracket \alpha \sim_{i} C \rrbracket_{f}^{g, h}$ is defined only if $g(C) \subseteq\left\{\llbracket \alpha \rrbracket_{f}^{g, h[x / i]} \mid x \in D_{e}\right\}$; if defined, $\llbracket \alpha \sim_{i} C \rrbracket_{f}^{g, h}=\llbracket \alpha \rrbracket_{f}^{g, h}$

The Q-operator in (49) is the interrogative complementizer head, which has the syntactic (LF) requirement that it must be co-indexed with a $w h$-item inside its complement and must not be co-indexed with any non-wh-item.

Given this setup, we can correctly analyze the declarative and interrogative complements of focus-sensitive preferential predicates. The desired interpretations of the declarative and interrogative complements are derived by the LFs in (51), as illustrated in (52):

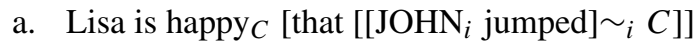

b. Lisa is happy ${ }_{C}$ (about) $\left[\mathrm{Q}_{i}\left[\left[\right.\right.\right.$ who $_{i}$ jumped $\left.\left.] \sim_{i} C\right]\right]$

a. 【that $\left[\left[\mathrm{JOHN}_{i}\right.\right.$ jumped] $\left.\sim_{i} C\right] \rrbracket_{o}^{g, h}$

is defined only if $g(C) \subseteq\left\{\lambda w \cdot \operatorname{jumped}_{w}(x) \mid x \in D_{e}\right\}$

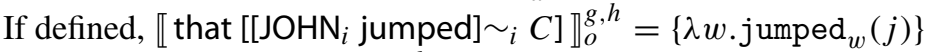

b. $\quad \llbracket \mathrm{Q}_{i}\left[\left[\mathrm{who}_{i}\right.\right.$ jumped $\left.\left.] \sim_{i} C\right]\right]_{o}^{g, h}$

is defined only if $g(C) \subseteq\left\{\lambda w \cdot \operatorname{jumped}_{w}(x) \mid x \in D_{e}\right\}$;

If defined, $\llbracket \mathrm{Q}_{i}\left[\left[\right.\right.$ who $_{i}$ jumped $\left.] \sim_{i} C\right] \rrbracket_{o}^{g, h}=\left\{\lambda w \cdot \operatorname{jumped}_{w}(x) \mid x \in D_{e}\right\}$

The system furthermore accounts for the fact that a non- $w h$ focus in an interrogative complement does not contribute to the interpretation of preferential predicates. In order for a focused non- $w h$-item to contribute to the interpretation of a preferential predicate, the $\sim$-operator constraining the variable $C$ must be co-indexed with the non-wh-focus. This could happen in the following two LFs.

a. *Lisa is happy ${ }_{C}\left[\mathrm{Q}_{i i}\left[\left[\mathrm{who}_{i}\right.\right.\right.$ saw $\left.\left.\left.\mathrm{BILL}_{i i}\right] \sim_{i i} C\right]\right]$

b. * Lisa is happy ${ }_{C}\left[\mathrm{Q}_{i}\left[\left[\mathrm{who}_{i}\right.\right.\right.$ saw BILL $\left.\left.\left.\mathrm{BL}_{i i}\right] \sim_{i i} C\right]\right]$

However, these LFs are ill-formed for the following reasons. The complement in (53a) violates the syntactic requirement that the Q-operator has to be co-indexed with a $w h$-item. Regarding (53b), we predict the following definedness condition and ordinary semantic value:

a. $\llbracket\left[\mathrm{who}_{i}\right.$ saw BILL $\left.{ }_{i i}\right] \sim_{i i} C \rrbracket_{o}^{g, h}$ is defined only if

$$
\begin{aligned}
& g(C) \subseteq\left\{\llbracket \text { who }_{i}\right. \text { saw BILL } \\
& i i \\
& \Leftrightarrow g(C) \subseteq\left\{\lambda w . \text { saw }_{w}(x)(h(i)) \mid x \in D_{e}\right\}
\end{aligned}
$$


b. If defined, $\llbracket \mathrm{Q}_{i}\left[\left[\mathrm{who}_{i}\right.\right.$ saw BILL $\left.\left._{i i}\right] \sim_{i i} C\right] \rrbracket_{o}^{g, h}=\left\{\lambda w \cdot \operatorname{saw}_{w}(h(i i))(y) \mid y \in\right.$ $\left.D_{e}\right\}$

What is crucial here is the fact that both (54a) and (54b) are dependent on the focusassignment function $h$. This goes against the following principle of interpretability from Beck (2006): ${ }^{18}$

\section{Principle of Interpretability}

a. An LF must have an ordinary semantic interpretation. (Beck 2006: 16)

b. An LF $\varphi$ has an ordinary semantic interpretation only if $\llbracket \varphi \rrbracket_{o}^{g}$ is defined.

The principle states that an LF is well-formed only if it has a defined ordinary semantic value independently of a focus-assignment function. This is not the case with (54) since both (54a) and (54b) are dependent on the focus-assignment function $h$ (i.e., contain free focus variables).

Finally, the system also rules out the following LF, where the $\sim$-operator scopes above the Q-operator.

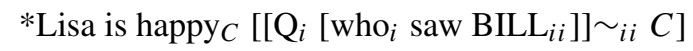

This stems from the mismatch in the semantic type of the ordinary semantic value of the interrogative complement and the $C$ variable. This is shown more concretely in the following:
a. $\llbracket\left[\mathrm{Q}_{i}\left[\mathrm{who}_{i}\right.\right.$ saw BILL $\left.\left.{ }_{i i}\right]\right] \sim_{i i} C \rrbracket_{o}^{g, h}$ is defined only if $g(C) \subseteq\left\{\left\{\lambda w \cdot \operatorname{saw}_{w}(x, y) \mid x \in D_{e}\right\} \mid y \in D_{e}\right\}$
b. If defined, $\llbracket\left[\mathrm{Q}_{i}\left[\mathrm{who}_{i}\right.\right.$ saw BILL $\left.\left.{ }_{i i}\right]\right] \sim_{i i} C \rrbracket_{o}^{g, h}=\left\{\lambda w \cdot \operatorname{saw}_{w}(x, b) \mid x \in\right.$ $\left.D_{e}\right\}$

As seen above, the $C$ variable is required to be a set of sets of propositions, while the ordinary semantic value of the complement is a set of propositions. This mismatch guarantees that (56) necessarily violates a presupposition triggered by the embedding preferential predicate, specifically the presupposition that a member of the ordinary complement denotation is a member of $C$, i.e., the third conjunct in the entry for be happy, repeated below.

$$
\begin{gathered}
\llbracket \text { be happy } \rrbracket^{w}=\lambda Q_{\widehat{\langle s, t\rangle}} \cdot \lambda x \cdot \lambda w: \exists p \in Q\left[p(w) \wedge \operatorname{believe}_{w}(x, p) \wedge p \in C\right] . \\
\exists p^{\prime \prime} \in Q\left[\begin{array}{c}
p^{\prime \prime}(w) \wedge \operatorname{believe}_{w}\left(x, p^{\prime \prime}\right) \wedge p^{\prime \prime} \in C \wedge \\
\operatorname{Pref}_{w}\left(x, p^{\prime \prime}\right)>\theta(C)
\end{array}\right]
\end{gathered}
$$

Hence, the mechanism of selective focus binding from Wold (1996) and Romero (2015) enables an appropriate treatment of the selective focus sensitivity of preferential predicates with declarative and interrogative complements.

\footnotetext{
18 The clause in (55b) is not explicitly stated in Beck's (2006) original formulation. However, it is implicitly present since an ordinary semantic value in her system is denoted by $\llbracket \cdot \rrbracket^{g}$, in contrast to the focus-semantic value $\llbracket \cdot \rrbracket^{g, h}$.
} 


\subsection{Exhaustivity}

The next issue concerns the exhaustivity of embedded questions. Our analysis of preferential predicates so far has only dealt with the so-called mention-some reading. That is, the analysis states that a sentence of the form $x$ is happy about $Q$ is true iff there is some true answer to $Q$ that bears the appropriate preferential relation to $x$. In fact, the mention-some semantics is crucial in the explanation of the anti-rogativity of non-veridical preferentials in Sect. 3.4. However, what is potentially problematic is the fact that embedded questions in principle allow a variety of stronger readings, e.g., weakly exhaustive, strongly exhaustive, and intermediate exhaustive readings (Groenendijk and Stokhof 1984; Heim 1994; Beck and Rullmann 1999; George 2011; Klinedinst and Rothschild 2011; Cremers 2016). How should we account for such stronger readings within the proposed theory of preferential predicates, and how do they affect the analysis of the anti-rogativity of non-veridical preferential predicates?

Presenting a comprehensive account of exhaustivity in questions under different embedding predicates is beyond the scope of this paper (see Theiler et al. 2018 for a recent review and proposal). Rather, we will limit our attention to the kinds of exhaustivity that are empirically attested under preferential predicates. Below, we briefly summarize our empirical assumptions about the attested kinds of question exhaustivity under preferential predicates, following the literature on the topic.

Our starting point is George's (2013) argument that all available data that have been argued to suggest weak exhaustivity, such as (58) (e.g. Beck and Rullmann 1999), are in fact compatible with mention-some readings.

Pat was happy about which students sang, but she wasn't happy about which student didn't sing.

We follow George (2013) on this point, and assume that there is no mechanism in the semantics of embedded questions that specifically derives weak exhaustivity, at least not under preferential predicates. Instead, a mention-some reading accounts for data such as (58).

Moving on to strong exhaustivity, although some researchers have argued that preferential predicates disallow strong exhaustivity (Beck and Rullmann 1999; Sharvit 2002), recent literature suggests that strong exhaustivity is in fact available under preferential predicates (Klinedinst and Rothschild 2011; Theiler 2014; Cremers and Chemla 2017). Below is an example from Klinedinst and Rothschild (2011: fn.18) that suggests that strong exhaustivity is available with surprise:

(59) Four students run a race: Bob, Ted, Alice, and Sue. Emily expects Bob, Ted, and Alice to run it in under six minutes. Only Bob runs it in under six minutes. Emily is surprised who ran the race in under six minutes (since she expected more people to).

Taking this type of data seriously, we assume that strong exhaustivity is an available reading under preferential predicates.

Finally, although it has been argued that epistemic predicates (e.g. know) and communication/conjecture predicates (e.g. predict) allow the so-called intermediate 
exhaustivity of embedded questions, ${ }^{19}$ there is no evidence suggesting that preferential predicates allow an intermediately exhaustive reading. For instance, no available evidence indicates that (60) has the intermediately exhaustive reading paraphrased in the quote.

(60) Pat is happy about which students sang.

\#"For all students who sang, Pat is happy that they sang; for all students who didn't sing, Pat didn't prefer that they sing."

The absence of intermediate exhaustivity with preferential predicates is also pointed out by Uegaki (2015) and Theiler et al. (2018).

All in all, we assume that preferential predicates allow mention-some and strongly exhaustive readings. The former is necessary to account for data such as (58), while the latter is necessary to account for data such as (59). On the other hand, there is no empirical evidence that semantics should derive weak- and intermediate-exhaustive readings for questions embedded under preferential predicates.

Given this empirical picture, what we need in addition to the analysis as it stands is a treatment of strong exhaustivity. We follow Romero (1998, 2016) and Spector (2007) in assuming that $w h$-phrases can optionally range over generalized quantifiers (GQs) in addition to entities, resulting in a 'higher-order' interpretation of a whclause. We propose that this interpretation of a $w h$-phrase is constructed by the basic interpretation which ranges over individuals in such a way that these individuals are first lifted to the corresponding GQs (Montagovian individuals) and then this set of GQs is closed under generalized Boolean operations. For any set of individuals $S$, the corresponding set of Montagovian individuals is given by $\uparrow=\{\uparrow x \mid x \in S\}=$ $\left\{\lambda w \cdot \lambda P_{\langle e, t\rangle} . P(x)=1 \mid x \in S\right\}$. Let us denote the generalized Boolean closure of this set by $\uparrow S^{\star}$. That is, $\uparrow S \subseteq \uparrow S^{\star}$, and for any $G_{1}, G_{2} \in \uparrow S^{\star},-G_{1}, G_{1} \sqcap G_{2}, G_{1} \sqcup G 2 \in$ $\uparrow S^{\star}$, where - is generalized negation, $\sqcap$ generalized conjunction, and $\sqcup$ generalized disjunction. $^{20}$

Concretely, the Hamblin-style question denotation involving such a GQinterpretation of who would look like the following:

19 The intermediate-exhaustive reading of a question embedded under know and predict can be paraphrased as follows:

(i) Pat knows which students sang.

"For all students who sang, Pat knows that they sang; for all students who did not sing, she does not believe that they sang."

(ii) Pat predicted which student would sing.

"For all students who sang, Pat predicted that they would sing; for all students who did not sing, she did not predict that they would sing."

See Cremers and Chemla (2016), Xiang (2016), and Theiler et al. (2018) for detailed empirical overviews on intermediate exhaustivity.

20 The generalized Boolean operators are standardly defined as follows:

(i) a. Type $t$ is a conjoinable type.

b. If $\sigma$ is a type and $\tau$ is a conjoinable type, $\langle\sigma, \tau\rangle$ is a conjoinable type.

(ii) Let $\tau$ be a conjoinable type, and let $\alpha$ and $\beta$ be expressions of type $\tau$. 
$\left\{\lambda w \cdot G\left(\lambda x . \operatorname{sang}_{w}(x)\right) \mid G \in \uparrow\right.$ person $\left.^{\star}\right\}$

'Which GQ $G \in \uparrow$ person ${ }^{\star}$ is such that $G\left(\lambda x . \operatorname{sang}_{w}(x)\right)$ is true?'

This denotation includes '(strongly-)exhaustified' answers such as 'Only Ann sang'. This is so because the $w h$-phrase contains in its domain the following generalized quantifier: $G=\lambda P_{e t} . P(\mathbf{a}) \wedge \bigwedge_{x \in\left(D_{e}-\{\mathbf{a}\}\right)} \neg P(x)$. With such an analysis of wh-complements in place, data like (59) can be accounted for, preserving the existential semantics for embedding predicates. The last sentence in (59) is judged true since, in the given context, there is a generalized quantifier $G$ such that $\lambda w . G(\lambda x . x$ ran the race in under six minutes in $w)$ is surprising to Emily; that is, the generalized quantifier is of the form $G=\lambda P_{e t} . P(\mathbf{b}) \wedge \bigwedge_{x \in\left(D_{e}-\{\mathbf{b}\}\right)} \neg P(x)$. Note that this mechanism only accounts for the optional strong exhaustivity of embedded questions, and that we need a different account for the obligatory strong exhaustivity of questions embedded under certain predicates, e.g. be certain. See Uegaki (2015) and Theiler et al. (2018) for explanations of the obligatory strong exhaustivity under be certain in terms of the lexical-semantic property of the predicate.

The above idea can be implemented within the theory of selective focus binding developed in the previous section. We first revise the definition of the focus-variable assignment function $h$ so that it maps certain indices to generalized quantifiers. In this paper, we designate the capital roman numerals (I, II, III...) as those indices that are mapped to generalized quantifiers by $h$ :

$$
\begin{aligned}
& \text { a. } \llbracket \text { who }_{I} \rrbracket_{o}^{g, h}=\text { undefined } \\
& \text { b. } \llbracket \text { who }_{I} \rrbracket_{f}^{g, h}=h(I)
\end{aligned}
$$$$
\text { where } h(I) \in \uparrow \text { person }{ }^{\star}
$$

Accordingly, we have the following higher-order definitions of the Q-operator and the -operator:

$$
\begin{aligned}
& \text { a. } \llbracket \mathrm{Q}_{I} \varphi \rrbracket_{o}^{g, h}=\left\{\llbracket \varphi \rrbracket^{g, h[G / I]} \mid G \in D_{\langle e t, t\rangle}\right\} \\
& \text { b. } \llbracket \mathrm{Q}_{I} \varphi \rrbracket_{f}^{g, h}=\llbracket \mathrm{Q}_{I} \varphi \rrbracket_{o}^{g, h} \\
& \llbracket \alpha \sim_{I} C \rrbracket_{o}^{g, h} \text { is defined only if } g(C) \subseteq\left\{\llbracket \alpha \rrbracket_{f}^{g, h[G / I]} \mid G \in D_{\langle e t, t\rangle}\right\} ;
\end{aligned}
$$$$
\text { if defined, } \llbracket \alpha \sim_{I} C \rrbracket_{o}^{g, h}=\llbracket \alpha \rrbracket_{o}^{g, h}
$$

As a result, we obtain the following definedness condition and the ordinary semantic value for the higher-order interpretation of a wh-complement:

Footnote 20 continued

$$
\begin{aligned}
& \text { a. } \quad-\alpha= \begin{cases}\neg \alpha & \text { if } \tau=t \\
\lambda x_{\sigma_{1}} .-\alpha(x) & \text { if } \tau=\left\langle\sigma_{1}, \sigma_{2}\right\rangle\end{cases} \\
& \text { b. } \alpha \sqcap \beta= \begin{cases}\alpha \wedge \beta & \text { if } \tau=t \\
\lambda x_{\sigma_{1}} . \alpha \sqcap \beta & \text { if } \tau=\left\langle\sigma_{1}, \sigma_{2}\right\rangle\end{cases} \\
& \text { c. } \alpha \sqcup \beta= \begin{cases}\alpha \vee \beta & \text { if } \tau=t \\
\lambda x_{\sigma_{1}} . \alpha \sqcup \beta & \text { if } \tau=\left\langle\sigma_{1}, \sigma_{2}\right\rangle\end{cases}
\end{aligned}
$$


$\llbracket \mathrm{Q}_{I}\left[\left[\right.\right.$ who $_{I}$ jumped $\left.] \sim_{I} C\right] \rrbracket_{o}^{g, h}$

is defined only if $g(C) \subseteq\left\{\lambda w . G\left(\lambda x \cdot \operatorname{jumped}_{w}(x)\right) \mid G \in \uparrow \operatorname{person}^{\star}\right\}$;

If defined, $\llbracket \mathrm{Q}_{I}\left[\left[\mathrm{who}_{I}\right.\right.$ jumped] $\left.\sim_{I} C\right] \rrbracket_{o}^{g, h}=\left\{\lambda w \cdot G\left(\lambda x \cdot \operatorname{jumped}_{w}(x)\right) \mid G \in\right.$ $\uparrow$ person $\left.{ }^{\star}\right\}$

As discussed above, this accounts for the strongly exhaustive interpretation of whcomplements embedded under preferential predicates. Also, note that the possibility of the higher-order interpretation does not affect the analysis of the anti-rogativity of non-veridical preferential predicates developed in Sect. 3. This is because we have preserved the existential semantics for preferential predicates. The embedding of an interrogative complement under a non-veridical preferential predicate with the existential semantics we developed in Sect. 3 predicts triviality, as long as the question denotation and the set of focus alternatives are equivalent. Such equivalence is guaranteed in (65).

\section{Nominalization and about}

One of the issues we left open in the empirical discussion in Sect. 2 is the potential complication posed by the preposition about. As shown in (66), interrogative complements under some veridical preferential predicates are optionally introduced with a preposition like about. In fact, a preposition seems to be preferred in many cases where there is such an option (Egré 2008; Mayr 2019).

a. Max likes which students are invited to the party.

b. Max is happy ?(about) which students are invited to the party.

c. Max is surprised (about/at) which students are invited to the party.

On the other hand, the presence or absence of about does not affect the ungrammaticality of non-veridical preferentials with interrogative complements, as shown below:

a. *Max prefers (about) which students are invited to the party.

b. *Max hopes/wishes (about) which students are invited to the party.

c. *Max expects (about) which students are invited to the party.

The data so far are compatible with the view that about in (66) is semantically vacuous and that its distribution is purely a matter of syntax. ${ }^{21}$ Under such a view, as long as a predicate is semantically incompatible with an interrogative complement, it cannot embed an interrogative complement regardless of the presence of about. However, such a view turns out to be too simplistic, once we start considering data involving other anti-rogative predicates that allow interrogative complements with the help of

\footnotetext{
21 Grimshaw (1990: Ch. 3) presents such a view, employing the notion of theta-marking, which we interpret to be a syntactic mechanism. According to this view, all arguments-whether nominal or clausal-must be theta-marked. However, some heads with argument structures do not have the theta-marking ability. Arguments to such a head can be assigned a theta-role by a preposition while semantically participating in the argument structure of the head.
} 
about, as in (68), and cases involving nominalizations of non-veridical preferential predicates, as in (69).

Pat thought *(about) who will be invited to the party.

a. Pat has (a) preference about who will be invited to the party.

b. Pat has (a) hope/wish about who will be invited to the party.

c. Pat has (an) expectation about who will be invited to the party.

In the rest of this section, we argue that the above data can be accounted for by employing Rawlins' (2013) 'non-orthogonality' semantics for about, but restricting its application to traditional adjuncts. To sketch the analysis more concretely, we will assume that there are two lexical entries for about: about $\varnothing$ and about $_{R}$, where $a b o u t_{\varnothing}$ is semantically vacuous while about $_{R}$ is the 'Rawlins-style' about denoting the nonorthogonality relation between two issues (to be elaborated below). An interrogative $\mathrm{CP}$ introduced by about $\varnothing$ is allowed as long as the predicate is semantically compatible with an interrogative complement, given the considerations discussed so far in this paper. On the other hand, an interrogative CP introduced by about $t_{R}$ is allowed only in an adjunction structure. Crucially, contra Rawlins, we argue that not all clauses embedded by about have an adjunction structure (and hence a non-orthogonality semantics). A further requirement is imposed by obligatory transitivity as a lexical specification of the predicate (Chomsky 1965). If a clause-embedding predicate is obligatorily transitive, it must merge with a complement clause, which may involve about $\varnothing$ but may not involve about $_{R}$.

\subsection{Rawlins (2013)-style analysis of about}

To elaborate on the analysis, we begin with our rendition of Rawlins' (2013) semantics for about. According to Rawlins, about denotes a relation between a question and an eventuality that holds if the question is non-orthogonal to the content of the eventuality. This is formally defined as follows: ${ }^{22,23}$

$$
\llbracket \operatorname{about}_{R} \rrbracket=\lambda Q_{\widehat{\langle s, t\rangle}} \cdot \lambda e_{v} \cdot \lambda w: e \in \operatorname{Dom}\left(\operatorname{Con}_{w}\right) . \neg \operatorname{Orthogonal}\left(Q, \operatorname{Con}_{w}(e)\right)
$$

\footnotetext{
22 Rawlins (2013) represents a content as an equivalence relation on a set of worlds, following an earlier formulation of propositions in inquisitive semantics (Groenendijk and Roelofsen 2009). Here, we will simply assume that a content is represented as a set of propositions, which may be denoted by an interrogative complement or by a declarative complement, as discussed in Sect. 3.1. Accordingly, the notion of orthogonality between two questions is redefined in terms of the consistency of every pair of propositions consisting of an answer (or the complement of the union of answers) to each of the two questions respectively.

23 Here, we specify in the type specification of the Con-function that its argument is an event. This specification makes the type calculation more transparent and correctly accounts for all cases considered in this section. However, it has potential problems in dealing with cases where the external argument of $a b o u t_{R}$ is an entity, as in (i) below:
}

(i) The email is about whether Joanna was going.

(Rawlins 2013: 341)

This problem can be avoided by defining Con as a function on entities and treating events as a sub-type of entities, as done by Rawlins (2013). 
a. $\operatorname{Con}_{w}(e)=$ the content of $e$ in $w \quad\left(\operatorname{Con}_{w}:\langle v, \widehat{\langle s, t\rangle}\rangle ; v\right.$ : the type for eventualities)

b. Orthogonal $\left(Q_{1}, Q_{2}\right)$

$\Leftrightarrow \forall p \in Q_{1} \cup\left\{W-\bigcup Q_{1}\right\} \forall p^{\prime} \in Q_{2} \cup\left\{W-\bigcup Q_{2}\right\}\left[p \cap p^{\prime} \neq \varnothing\right]$

Rawlins (2013) assumes an event-semantic analysis of clause-embedding predicates (e.g., Kratzer 2006; Hacquard 2006), according to which attitudinal and speech-report predicates are one-place predicates of content-bearing eventualities. For example, talk is analyzed as follows:

$$
\llbracket \text { talk } \rrbracket=\lambda e_{v} \cdot \lambda w: e \in \operatorname{Dom}\left(\operatorname{Con}_{w}\right) . \operatorname{Talking}_{w}(e)
$$

Given the entry for about in (70) and the event-predicate analysis of talk in (71), we can analyze talk-about plus an interrogative complement as involving an event-predicate modification. (72) describes the type-driven composition, and (73) the resulting VP interpretation of talk about who sang.

Modification with about $_{R}-P P$

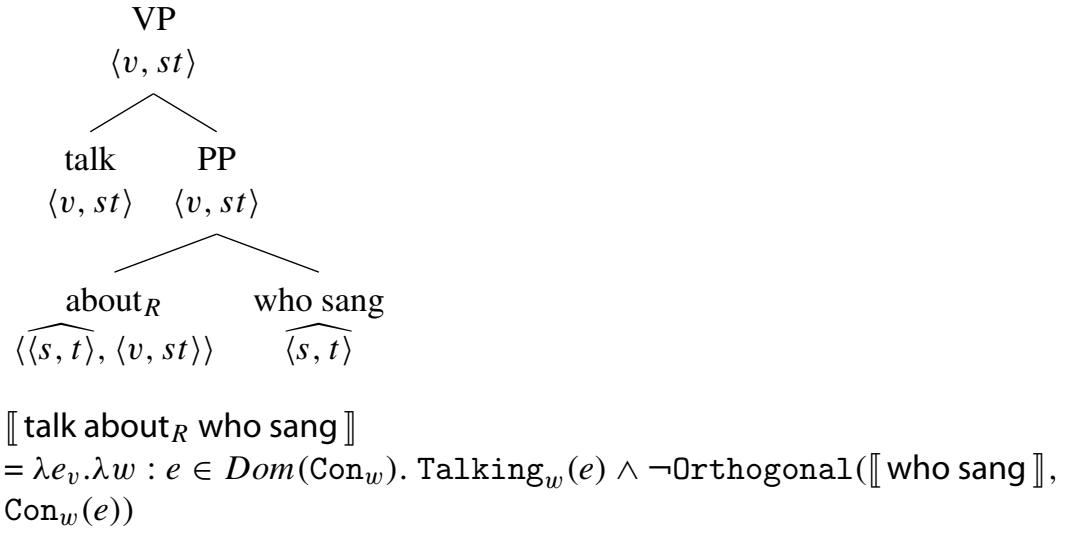

The resulting VP interpretation in (73) is a predicate that is true of talking events whose content is non-orthogonal to who sang.

\subsection{About-PP as a true complement}

The semantics of about $_{R}$-PPs described above has sufficient flexibility to apply to occurrences of about in the complement of other clause-embedding predicates. In particular, Rawlins (2013) argues that about $_{R}$ appears in the (traditional) complement of veridical preferentials such as surprise, based on the analysis of complementation structure by Kratzer (2006) and Hacquard (2006).

However, it turns out that treating the about-PPs in complements of veridical preferentials along the lines of Rawlins (2013) predicts interpretations that are too weak. To see this, consider the following lexical entry for an emotive factive predicate under the Kratzer-Hacquard-style analysis of attitudes:

$$
\llbracket \text { happy } \rrbracket=\lambda e \cdot \lambda w \cdot \operatorname{happy}_{w}\left(\operatorname{Hldr}_{w}(e), \operatorname{Con}_{w}(e)\right) \quad(\text { Kratzer-Hacquard style })
$$


Under this analysis, be happy denotes a predicate of eventualities that holds of an eventuality if its holder is in the happy-relationship with the content of that eventuality. Here, happy is a relationship between an individual and a question-type content which may have the kind of analysis for be happy we developed in earlier sections. However, the point we are going to make can be made without committing to a particular analysis of the predicate happy.

In Kratzer's (2006) decompositional semantics for attitudes followed by Rawlins, a that-clause serves as an eventuality-modifier that specifies the content of the relevant eventuality. Thus, given the lexical entry for be happy in (74), we derive the following truth conditions for a declarative-embedding sentence with be happy.

$$
\begin{aligned}
& \llbracket \text { Max is happy that Ann was invited } \rrbracket=\lambda w . \exists e\left[\operatorname{Hldr}_{w}(e)=m \wedge \operatorname{Con}_{w}(e)\right. \\
& \left.=\{\llbracket \text { Ann was invited } \rrbracket\} \wedge \operatorname{happy}_{w}\left(\operatorname{Hldr}_{w}(e), \operatorname{Con}_{w}(e)\right)\right]
\end{aligned}
$$

This is arguably an adequate analysis of the declarative-embedding case. However, the prediction for the about $+w h$ case, given in (76) below, is problematic.

$$
\begin{aligned}
& \llbracket \text { Max is happy about who was invited } \rrbracket=\lambda w \cdot \exists e\left[\operatorname{Hldr}_{w}(e)=m\right. \\
& \wedge \neg \text { Orthogonal( }\left(\llbracket \text { who was invited } \rrbracket, \operatorname{Con}_{w}(e)\right) \wedge \operatorname{happy}_{w}\left(\operatorname{Hldr}_{w}(e),\right. \\
& \left.\left.\operatorname{Con}_{w}(e)\right)\right]
\end{aligned}
$$

According to (76), the sentence is true as long as the content of Max's happiness is nonorthogonal to the question 'who was invited'. This incorrectly predicts the sentence to be true in the following situation:

(77) CONTEXT: Emily is a good old friend of Max. Max is happy whenever Emily is happy, and he is happy whenever he is with her. Their mutual friend Paul is going to throw a singles party. Being single, Max is invited to the party. Emily isn't invited since she recently started dating someone from her yoga class. Max is happy that Emily is no longer single, but he is also sad that Emily won't be at the party.

In (77), the proposition 'Emily is not single' is non-orthogonal to the question 'Who is invited to the party' because the former partially resolves the latter. This means that the truth conditions in (76) are satisfied in (77), given that Max is happy that Emily is not single. This is so since the situation whose content is the singleton set of the proposition 'Emily is not single' meets all the conditions of existential quantification in (76). However, this prediction is not borne out. In the situation described in (76), the sentence Max is happy about who was invited does not sound true.

What the above data suggests is that the about-PP complement of be happy does not merely provide a content that is non-orthogonal to the content of happiness, but rather the content of happiness itself. To capture this fact, we posit the semantically vacuous about $\varnothing$, and analyze be happy as selecting for a complement providing the content in its lexical semantics, as follows:

$$
\begin{aligned}
& \llbracket \text { be happy } C \rrbracket= \\
& \lambda Q_{\widehat{\langle s, t\rangle}} \cdot \lambda e \cdot \lambda w: \operatorname{Con}_{w}(e)=Q \wedge \exists p \in \operatorname{Con}_{w}(e)\left[p(w) \wedge \text { believe }_{w}\right.
\end{aligned}
$$




$$
\begin{gathered}
\left.\left(\operatorname{Hldr}_{w}(e), p\right) \wedge p \in C\right] \\
\exists p^{\prime \prime} \in \operatorname{Con}_{w}(e)\left[\begin{array}{c}
p^{\prime \prime}(w) \wedge \operatorname{believe}_{w}\left(\operatorname{Hldr}_{w}(e), p^{\prime \prime}\right) \wedge p^{\prime \prime} \in C \wedge \\
\operatorname{Pref}_{w}\left(\operatorname{Hldr}_{w}(e), p^{\prime \prime}\right)>\theta(C)
\end{array}\right]
\end{gathered}
$$

This entry is an event-semantic rendition of our previous entry for be happy in (26), but, crucially, with the internal argument position, pace the Kratzer-Hacquard-style analysis. Given the semantically vacuous about $\varnothing$ and (78), we derive the interpretation for the AP happy about $\varnothing$ who was invited as follows:

Complementation with about $\varnothing$

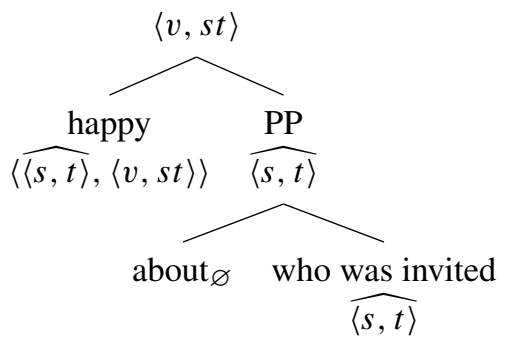

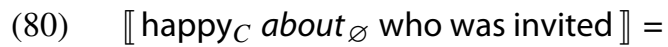

$\lambda e . \lambda w: \operatorname{Con}_{w}(e)=\llbracket$ who was invited $\rrbracket \wedge \exists p \in \operatorname{Con}_{w}(e)[p(w) \wedge$ $\left.\operatorname{believe}_{w}\left(\operatorname{Hldr}_{w}(e), p\right) \wedge p \in C\right]$.

$\exists p^{\prime \prime} \in \operatorname{Con}_{w}(e)\left[\begin{array}{c}p^{\prime \prime}(w) \wedge \operatorname{believe}_{w}\left(\operatorname{Hldr}_{w}(e), p^{\prime \prime}\right) \wedge p^{\prime \prime} \in C \wedge \\ \operatorname{Pref}_{w}\left(\operatorname{Hldr}_{w}(e), p^{\prime \prime}\right)>\theta(C)\end{array}\right]$

This analysis correctly captures the fact that the about-PP provides the content of the happiness itself rather than something that is non-orthogonally related to it. Note that about $_{R}$ cannot appear in the complement position of happy, due to type mismatch. This is illustrated in the following:

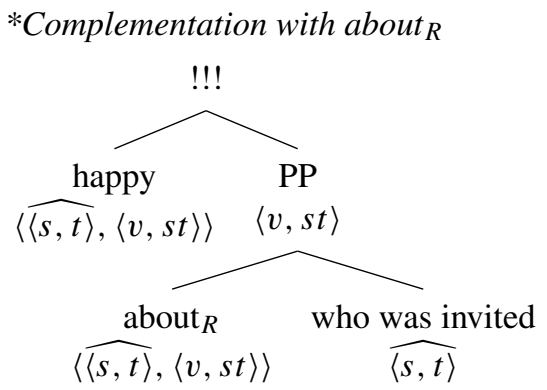

Thus, this analysis captures the unavailability of the weak reading predicted by the Rawlins-style analysis.

\subsection{Obligatory transitivity}

Above, we have seen that an about-PP can in principle be an event modifier involving about $_{R}$ or a true complement involving about $\varnothing$. Also, we have argued that the occurrence of about-PPs under veridical preferential predicates such as happy and 
be surprised is better analyzed as cases of true complements with about $\varnothing$. We will now show that the rest of the data introduced in the beginning of this section (repeated below) can also be fully captured in this setup, once we take into account the transitivity of the predicates.

(67) a. *Max prefers (about) which students are invited to the party.

b. *Max hopes/wishes (about) which students are invited to the party.

c. *Max expects (about) which students are invited to the party.

(68) Pat thought *(about) who will be invited to the party.

(69) a. Pat has a preference about who will be invited to the party.

b. Pat has a hope/wish about who will be invited to the party.

c. Pat has an expectation about who will be invited to the party.

In our setup, whether a clause-embedding predicate is transitive or not is reflected in its semantic type. A transitive predicate has type $\langle\widehat{\langle s, t\rangle},\langle v, s t\rangle\rangle$, just like happy in (78), while an intransitive predicate has type $\langle v, s t\rangle$, just like talk in (71). A predicate's transitivity can be tested independently of its compatibility with about-PPs and its anti-rogative/responsive status. If a predicate can occur without any complement, it is either intransitive or optionally transitive; if a predicate must occur with some kind of complement, it is obligatorily transitive.

The predicates in (67) are all obligatorily transitive, as the ungrammaticality of the following examples suggests.
a. *Max prefers.
b. *Max hopes/wishes.
c. *Max expects.

This means that these predicates have $\langle\widehat{\langle s, t\rangle},\langle v, s t\rangle\rangle$-type lexical entries. As discussed in relation to (81) in the previous subsection, a transitive predicate is incompatible with an about $_{R}$-PP for type reasons. Furthermore, we have shown in the discussion above that non-veridical preferential predicates cannot embed interrogative complements due to the predicted semantic triviality. This is true whether or not the interrogative complement involves a semantically vacuous about $\varnothing$. We thus capture the ungrammaticality of (67) observed both with and without about.

Moving on to the predicates in (68), the following examples suggest that they are intransitive or optionally transitive.

\section{Pat thought for a moment.}

This means that there exist $\langle v, s t\rangle$-type entries for think. An about $t_{R}$-PP is typewise compatible with these entries, semantically providing a content that is nonorthogonally related to the content of thought. This accounts for the acceptability of interrogative complements with about in (68). ${ }^{24}$

\footnotetext{
24 It is worth noting that the notion of (obligatory) transitivity is independently invoked by Rawlins (2013) to account for the following selection pattern involving think and believe (following a suggestion by $\mathrm{P}$. Portner, pers. comm. to Rawlins):
} 
Finally, the data in (69) fall out straightforwardly once we take into account the status of argument structures for deverbal nouns. As Grimshaw (1990) famously shows, a deverbal noun is ambiguous between an interpretation that involves a full-fledged argument structure (COMPLEX EVENT NOMINAL; CEN) and other interpretations that lack an argument structure (SIMPLE EVENT NOMINAL; SEN, and RESULT NOMINAL; $\mathrm{RN}$ ). The possibility of interpretations without argument structure explains the compatibility of deverbal nouns with an about $+w h$-clause, regardless of the properties of the predicates they are derived from.

Specifically, following Moulton (2014), we assume that a SEN denotes a one-place predicate of events, as follows.

$$
\begin{aligned}
& \llbracket\left[\mathrm{nP} \mathrm{n} \sqrt{\operatorname{hope}_{C}}\right] \rrbracket \\
& =\lambda e . \lambda w: \exists p \in \operatorname{Con}_{w}(e)[p \in C] . \exists p^{\prime \prime} \in \operatorname{Con}_{w}(e)\left[p^{\prime \prime} \in C \wedge\right. \\
& \left.\left.\operatorname{Pref}_{w}\left(\operatorname{Hldr}_{w}(e), p^{\prime \prime}\right)>\theta(C)\right]\right]
\end{aligned}
$$

Here, $\mathrm{n}$ is the SEN-nominalizer, which existentially closes off the internal argument of the root in Moulton's (2014) analysis. The denotation in (84) can be compositionally derived by assuming (a) Moulton's (2014) analysis of the SEN-nominalizer and (b) the event-semantic rendition of our entry for hope in (34) as the denotation of the root $\sqrt{\text { hope }}^{25}$

Given this denotation for the noun hope we can account for the about+wh-clause as an adjunct involving about $t_{R}$. The type-driven composition of such an adjunction structure is depicted in (85), with the interpretation in (86).

NP-adjunction with about ${ }_{R}$

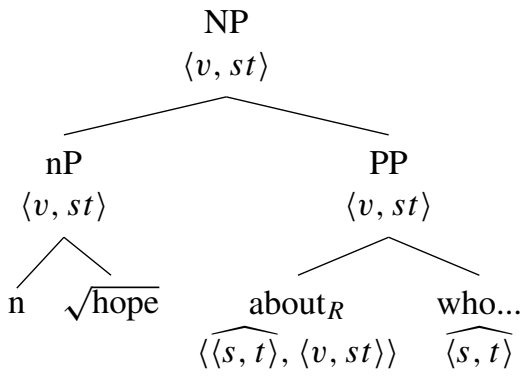

Footnote 24 continued

(i) a. Alfonso thought about Joanna.

b. *Alfonso believed about Joanna.

c. Alfonso believed about Joanna that she was clever.

(Rawlins 2013: 340, fn. 5)

The contrast between think and believe here can be explained by the fact that think is not obligatorily transitive while believe is.

25 For the purpose of our argument, it suffices that deverbal nouns have an interpretation devoid of argument structure, as in (84), as one of the possible readings. Though see Moulton (2014) for an argument that CPtaking deverbal nouns such as the noun hope do not have the CEN reading, i.e., they always lack an argument structure. 


$$
\begin{aligned}
& \llbracket\left[\mathrm{nP} \mathrm{n} \sqrt{\mathrm{hope}_{C}}\right]\left[\mathrm{PP} \text { about }_{R} \text { who...] }\right] \\
& =\lambda e . \lambda w: \exists p \in \operatorname{Con}_{w}(e)[p \in C] . \exists p^{\prime \prime} \in \operatorname{Con}_{w}(e)\left[p ^ { \prime \prime } \in C \wedge \operatorname { P r e f } _ { w } \left(\operatorname{Hldr}_{w}(e),\right.\right. \\
& \left.\left.p^{\prime \prime}\right)>\theta(C)\right] \wedge \neg \text { Orthogonal }(\llbracket \text { who... } \rrbracket, \operatorname{Con}(e))
\end{aligned}
$$

Here, non-veridical preferentiality of the root noun $\sqrt{\text { hope }}$ does not lead to any semantic triviality. This is so since the content of the hope itself in (86) need not have the form of a question; it just needs to be non-orthogonally related to a question. For example, the content of the hope can be that Max will be invited to the party, which is non-orthogonally related to the question of who will be invited to the party.

In sum, the initially puzzling selection behavior involving the preposition about in (67)-(69) can be accounted for as a result of the interplay between the ambiguity of about between the non-orthogonality reading (Rawlins 2013) and a semantically vacuous reading, and the transitivity of the predicates.

It should be mentioned that reliance on obligatory transitivity creates a potential problem with our analysis of predicates such as be happy and be surprised in Sect. 5.2 - that is, with the notion that they can take an about $\varnothing-\mathrm{PP}$ as a true complement. Since these predicates can appear without any CP complement, as in (87), they must have type $\langle v, s t\rangle$ lexical entries.
a. Max is happy.
b. Max is surprised.

Given the proposed analysis, this in turn means that they can combine with an about $_{R^{-}}$ $\mathrm{PP}$ as an adjunct, which might appear to conflict with our analysis of these predicates in Sect. 5.2. However, it is possible that these predicates are optionally transitive, just like eat, i.e., they may be able to take an about $_{\varnothing}-\mathrm{PP}$ as a true complement while also optionally appearing without any complement. Treating these predicates as optionally transitive accounts for their selectional properties, including the data in (87). Nevertheless, something has to be said about the interpretation of sentences containing be happy+about-wh (discussed in relation to the context involving the singles party in (77)), which suggests that the reading involving an about $\varnothing$-complement rather than the one involving an about $_{R}$-adjunct is the default option. We suggest that this is due to the Strongest Meaning Hypothesis (Dalrymple et al. 1998), a general pragmatic principle to the effect that the strongest available interpretation is preferred. The reading with about $\varnothing$ is stronger than that with about $_{R}$ unless the sentence is embedded under a non-upward-entailing operator. Note that the possibility of optional transitivity does not pose any problem for our analysis of about-wh under nominalizations of non-veridical preferentials (e.g., preference about who will be invited). This is so since the about $_{\varnothing}$-complementation option, even if it is type-wise available, is ruled out because of semantic triviality.

\section{Conclusions}

In this paper, we have put forward a hypothesis that all non-veridical preferential predicates are anti-rogative, and provided a semantic analysis that derives this hypothesis using a uniform semantics of clausal-embedding predicates (Ciardelli et al. 2013; 
Uegaki 2015; Theiler et al. 2018) and a degree-based semantics for preferential predicates (Romero 2015). The paper thus advances the current research into the semantic roots of selectional restrictions (Ciardelli and Roelofsen 2015; Uegaki 2015; Theiler et al. 2019; Mayr 2019).

Open Access This article is distributed under the terms of the Creative Commons Attribution 4.0 International License (http://creativecommons.org/licenses/by/4.0/), which permits unrestricted use, distribution, and reproduction in any medium, provided you give appropriate credit to the original author(s) and the source, provide a link to the Creative Commons license, and indicate if changes were made.

\section{References}

Abels, Klaus. 2004. Why surprise-predicates do not embed polar interrogatives. Linguistische Arbeitsberichte 81: 203-222.

Abrusán, Márta. 2019. Semantic anomaly, pragmatic infelicity, and ungrammaticality. Annual Review of Linguistics 5: 329-351.

Anand, Pranav, and Valentine Hacquard. 2013. Epistemics and attitudes. Semantics and Pragmatics 6 (8): $1-59$.

Barwise, Jon, and Robin Cooper. 1981. Generalized quantifiers and natural language. Linguistics and Philosophy 4 (2): 159-219.

Beaver, David I., and Brady Z. Clark. 2008. Sense and sensitivity: How focus determines meaning. Chichester: Wiley-Blackwell.

Beck, Sigrid. 2006. Intervention effects follow from focus interpretation. Natural Language Semantics 14 (1): $1-56$.

Beck, Sigrid, and Hotze Rullmann. 1999. A flexible approach to exhaustivity in questions. Natural Language Semantics 7 (3): 249-298.

Bolinger, Dwight. 1968. Post-posed main phrases: An English rule for the Romance subjunctive. Canadian Journal of Linguistics 14 (1): 3-30.

Chierchia, Gennaro. 2013. Logic in grammar: Polarity, free choice, and intervention. Oxford: Oxford University Press.

Chomsky, Noam. 1965. Aspects of the theory of syntax. Cambridge, MA: MIT Press.

Ciardelli, Ivano, Jeroen Groenendijk, and Floris Roelofsen. 2013. Inquisitive semantics: A new notion of meaning. Language and Linguistics Compass 7 (9): 459-476.

Ciardelli, Ivano, and Floris Roelofsen. 2015. Inquisitive dynamic epistemic logic. Synthese 192 (6): 16431687.

Cremers, Alexandre. 2016. On the semantics of embedded questions. PhD thesis, École Normale Supérieure, Paris.

Cremers, Alexandre, and Emmanuel Chemla. 2016. A psycholinguistic study of the exhaustive readings of embedded questions. Journal of Semantics 33 (1): 49-85.

Cremers, Alexandre, and Emmanuel Chemla. 2017. Experiments on the acceptability and possible readings of questions embedded under emotive-factives. Natural Language Semantics 25: 223-261.

Dalrymple, Mary, Makoto Kanazawa, Yookyung Kim, Sam Mchombo, and Stanley Peters. 1998. Reciprocal expressions and the concept of reciprocity. Linguistics and Philosophy 21 (2): 159-210.

d'Avis, Franz-Josef. 2002. On the interpretation of wh-clauses in exclamative environments. Theoretical Linguistics 28 (1): 5-31.

Dayal, Veneeta. 1996. Locality in WH quantification: Questions and relative clauses in Hindi. Dordrecht: Kluwer.

Egré, Paul. 2008. Question-embedding and factivity. Grazer Philosophische Studien 77 (1): 85-125.

Gajewski, Jon. 2002. L-analyticity and natural language. Ms., MIT.

George, B.R. 2011. Question embedding and the semantics of answers. PhD thesis, University of California Los Angeles.

George, B.R. 2013. Which judgments show weak exhaustivity? (And which don't?). Natural Language Semantics 21 (4): 401-427. 
Grimshaw, Jane. 1979. Complement selection and the lexicon. Linguistic Inquiry 10 (2): 279-326.

Grimshaw, Jane. 1990. Argument structure. Cambridge, MA: MIT Press.

Groenendijk, Jeroen and Floris Roelofsen. 2009. Inquisitive semantics and pragmatics. In Meaning, content, and argument: Proceedings of the ILCLI international workshop on semantics, pragmatics, and rhetoric, ed. J. M. Larrazabal and L. Zubeldia. www.illc.uva.nl/inquisitivesemantics.

Groenendijk, Jeroen and Martin Stokhof. 1984. Studies on the semantics of questions and the pragmatics of answers. PhD thesis, University of Amsterdam.

Grohne, Gisela. 2017. Aspect and embedded questions. Talk presented at the workshop 'Inquisitiveness below and beyond the sentence boundary 1', Broek in Waterland.

Guerzoni, Elena. 2007. Weak exhaustivity and 'whether': A pragmatic approach. In Proceedings from SALT 17, ed. T. Friedman and M. Gibson, 112-129. Ithaca, NY: CLC Publications.

Hacquard, Valentine. 2006. Aspects of modality. PhD thesis, MIT.

Hamblin, Charles Leonard. 1973. Questions in Montague grammar. Foundations of Language 10: 41-53.

Harner, Hillary Jane. 2016. Focus and the semantics of desire predicates and directive verbs. PhD thesis, Georgetown University.

Heim, Irene. 1992. Presupposition projection and the semantics of attitude verbs. Journal of Semantics 9 (3): 183-221.

Heim, I. 1994. Interrogative semantics and Karttunen's semantics for know. In Proceedings of IATL 1, ed. R. Buchalla and A. Mittwoch, 128-144. Jerusalem: IATL.

Huddleston, Rodney, and Geoffrey K. Pullum. 2002. The Cambridge grammar of the English language. Cambridge: Cambridge University Press.

Karttunen, Lauri. 1977. Syntax and semantics of questions. Linguistics and Philosophy 1: 3-44.

Klinedinst, Nathan, and Daniel Rothschild. 2011. Exhaustivity in questions with non-factives. Semantics and Pragmatics 4 (2): 1-23.

Kratzer, Angelika. 2006. Decomposing attitude verbs. Handout from a talk honoring Anita Mittwoch on her 80th birthday at the Hebrew University of Jerusalem, July 4, 2006.

Kratzer, Angelika, and Junko Shimoyama. 2002. Indeterminate pronouns: The view from Japanese. In Proceedings of the 3rd Tokyo conference on psycholinguistics, ed. Y. Otsu, 1-25. Tokyo: Hituzi Syobo.

Lahiri, Utpal. 2002. Questions and answers in embedded contexts. Oxford: Oxford University Press.

Lassiter, Daniel, and Noah Goodman. 2017. Adjectival vagueness in a Bayesian model of interpretation. Synthese 194: 3801-3836.

Mayr, Clemens. 2019. Triviality and interrogative embedding: Context sensitivity, factivity, and neg-raising. Natural Language Semantics 27 (3): 227-278.

Moulton, Keir. 2014. Simple event nominalizations: Roots and their interpretation. In Cross-linguistic investigations of nominalization patterns, ed. I. Paul, 119-144. Amsterdam: John Benjamins.

Nicolae, Andreea Cristina. 2013. Any questions? Polarity as a window into the structure of questions. PhD thesis, Harvard.

Pesetsky, David. 1982. Paths and categories. PhD thesis, MIT.

Pesetsky, David. 1991. Zero syntax, vol. 2: Infinitives. Ms., MIT.

Portner, Paul, and Aynat Rubinstein. 2012. Mood and contextual commitment. In Proceedings of SALT 22, ed. A. Chereches, 461-487. Ithaca, NY: CLC Publications.

Qing, Ciyang, and Michael Franke. 2014. Gradable adjectives, vagueness, and optimal language use: A speaker-oriented model. In Proceedings of SALT 24, ed. T. Snider, S. D'Antonio, and M. Weigand, 23-41. Washington, DC: LSA.

Rawlins, Kyle. 2013. About 'about'. In Proceedings of SALT 23, ed. T. Snider, 336-357. Ithaca, NY: CLC Publications.

Roelofsen, Floris. (2019). Surprise for Lauri Karttunen. In Lauri Karttunen Festschrift, ed. C. Condoravdi. Stanford, CA: CSLI. https://www.press.uchicago.edu/ucp/books/book/distributed/T/bo45997447. html.

Roelofsen, Floris, Michele Herbstritt, and Maria Aloni. 2019. The *whether puzzle. In Questions in discourse, ed. K. von Heusinger, E. Onea, and M. Zimmermann, 172-197. Leiden: Brill.

Romero, Maribel. 1998. Focus and reconstruction effects in wh-phrases. PhD thesis, University of Massachusetts at Amherst.

Romero, Maribel. 2015. Surprise-predicates, strong exhaustivity and alternative questions. In Proceedings of SALT 25, ed. S. D’Antonio, M. Moroney, and C. Little, 225-245. Washington, DC: LSA. 
Romero, Maribel. 2016. Strong exhaustivity, alternative questions and monotonicity: Some thoughts on Cremers and Chemla (2016). Handout presented at the XPrag workshop 'Disjunction Days: Theoretical and experimental perspectives on the semantics and pragmatics of disjunction'. ZAS Berlin, June 2016.

Rooth, Matts. 1992. A theory of focus interpretation. Natural Language Semantics 1 (1): 75-116.

Ross, John Robert. 1967. Constraints on variables in syntax. PhD thesis, MIT.

Rubinstein, Aynat. 2012. Roots of modality. PhD thesis, University of Massachusetts at Amherst.

Sæbø Kjell Johan. 2007. A whether forecast. In Logic, language, and computation, ed. B. ten Cate and H. Zeevat, 189-199. Berlin: Springer.

Schwabe, Kerstin, and Robert Fittler. 2009. Semantic characterizations of German question-embedding predicates. In TbiLLC 2007: Logic, language, and computation, ed. P. Bosch, D. Gabelaia, and J. Lang, 229-241. Berlin: Springer.

Sharvit, Yael. 2002. Embedded questions and 'de dicto' readings. Natural Language Semantics 10 (2): 97-123.

Spector, Benjamin. 2007. Modalized questions and exhaustivity. In Proceedings of SALT 17, $282-299$. Ithaca, NY: CLC Publications.

Spector, Benjamin, and Paul Egré. 2015. A uniform semantics for embedded interrogatives: An answer, not necessarily the answer. Synthese 192 (6): 1729-1784.

Theiler, Nadine. 2014. A multitude of answers: Embedded questions in typed inquisitive semantics. MSc thesis, University of Amsterdam.

Theiler, Nadine, Floris Roelofsen, and Maria Aloni. 2018. A uniform semantics for declarative and interrogative complements. Journal of Semantics 35 (3): 409-466.

Theiler, Nadine, Floris Roelofsen, and Maria Aloni. 2019. Picky predicates: Why believe doesn't like interrogative complements, and other puzzles. Natural Language Semantics 27 (2): 95-134.

Tonhauser, Judith, David Beaver, Craige Roberts, and Mandy Simons. 2013. Toward a taxonomy of projective content. Language 89 (1): 66-109.

Uegaki, Wataru. 2015. Interpreting questions under attitudes. PhD thesis, MIT.

van Benthem, Johan. 1989. Logical constants across types. Notre Dame Journal of Formal Logic 30 (3): 315-342.

Villalta, Elisabeth. 2008. Mood and gradability: An investigation of the subjunctive mood in Spanish. Linguistics and Philosophy 31 (4): 467-522.

White, Aaron Steven, and Kyle Rawlins. 2016. A computational model of S-selection. In Proceedings of SALT 26, ed. M. Moroney, C.-R. Little, J. Collard, and D. Burgdorf, 641-663. Washington, DC: LSA.

Wold, Dag E. 1996. Long distance selective binding: The case of focus. In Proceedings of SALT 6, ed. T. Galloway, and J. Spence, 311-328. Ithaca, NY: CLC Publication.

Xiang, Yimei. 2016. Complete and true: A uniform analysis for mention-some and mention-all questions. In Proceedings of Sinn und Bedeutung 20, ed. N. Bade, P. Berezovskaya, and A. Schöller, 815-832. Tübingen: University of Tübingen.

Zuber, Richard. 1982. Semantic restrictions on certain complementizers. In Proceedings of the 13th International Congress of Linguists, ed. S. Hattori and K. Inoue, 434-436. Tokyo: Proceedings Publication Committee.

Publisher's Note Springer Nature remains neutral with regard to jurisdictional claims in published maps and institutional affiliations. 